\title{
Experimental Investigation of Fe-Co-La System: Liquidus and Solidus Projections
}

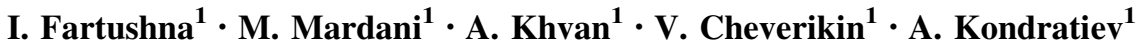

Submitted: 10 January 2020/in revised form: 17 March 2020/Published online: 20 April 2020

(C) ASM International 2020

\begin{abstract}
Phase equilibria in the Co-Fe-La system were studied using differential thermal analysis (DTA), X-ray diffraction analysis, scanning electron microscopy (SEM), and electron probe microanalysis (EPMA). Liquidus and solidus projections and a melting diagram for this system over the whole concentration range and a Scheil diagram for solidification were constructed. The ternary compound $(\mathrm{Co}, \mathrm{Fe})_{17} \mathrm{La}_{2}(\tau)\left(\mathrm{Th}_{2} \mathrm{Zn}_{17}\right.$-type structure $)$ forms by peritectic reaction $\mathrm{L}+(\gamma \mathrm{Co}, \mathrm{Fe})+\mathrm{Co}_{13} \mathrm{La} \rightleftarrows \tau$ at $978{ }^{\circ} \mathrm{C}$. This ternary compound is located along the isoconcentrate of 11 at. $\% \mathrm{La}$ and extends from 45.8 to 79.3 at.\% Co. The $\mathrm{Co}_{13} \mathrm{La}$ phase has the widest homogeneity region and dissolves up to 43.3 at.\% Fe. The solubilities of $\mathrm{Fe}$ in $\mathrm{Co}_{5} \mathrm{La}$, $\mathrm{Co}_{7} \mathrm{La}_{2}, \mathrm{Co}_{19} \mathrm{La}_{5}$, and $\mathrm{Co}_{3} \mathrm{La}_{2}$ were established to be 10.3 , 9.2, 4.7, and 3.2 at.\%, respectively. The solubility of Fe in $\mathrm{Co}_{1.7} \mathrm{La}_{2}$ and $\mathrm{CoLa}_{3}$ according to EPMA does not exceed 1 at.\%. The maximum solubility of $\mathrm{La}$ in $(\gamma \mathrm{Co}, \mathrm{Fe})$ and $(\alpha \mathrm{Co}, \mathrm{Fe})$ is determined to be less than 1 at. $\%$.
\end{abstract}

Keywords $\mathrm{Co}-\mathrm{Fe}-\mathrm{La} \cdot \mathrm{Co}-\mathrm{La} \cdot$ Liquidus surface $\cdot$ Phase diagrams $\cdot$ Solidus surface

This invited article is part of a special tribute issue of the Journal of Phase Equilibria and Diffusion dedicated to the memory of Günter Effenberg. The special issue was organized by Andrew Watson, Coventry University, Coventry, United Kingdom; Svitlana Iljenko, MSI, Materials Science International Services GmbH, Stuttgart, Germany; and Rainer Schmid-Fetzer, Clausthal University of Technology, Clausthal-Zellerfield, Germany.

\section{Fartushna}

juliefart@mail.ru

1 Thermochemistry of Materials Scientific Research Centre, NUST MISIS, Moscow, Russia

\section{Introduction}

Rare-earth (R) and transition-metal (M) compounds have many potential applications such as the production of permanent magnets ${ }^{[1,2]}$ as well as practical applications in a number of important high-technology branches of modern industry including solid-state electronics, aviation and space technology, and nuclear energy, among others. Permanent magnets based on rare-earth metals such as $\mathrm{RCo}_{5}$, $\mathrm{R}_{2} \mathrm{Co}_{7}$, and $\mathrm{R}_{2} \mathrm{Co}_{17}$ have very high magnetic crystallographic anisotropy and are characterized by record values of coercive force. ${ }^{[1,3-7]}$

R-TM alloys are well established as hydrogen-storage materials due to their excellent performance, being applied as such in engines and automobiles due to their good ability to absorb hydrogen. ${ }^{[8,9]}$ However, data on the phase equilibria and types of transformations in the R-Fe-TM and R$\mathrm{Fe}-\mathrm{C}$ systems remain limited, and information on the phase equilibria in these systems during crystallization is practically absent. Thus, obtaining systematic information on the phase diagrams of the $\mathrm{R}-\mathrm{Fe}-\mathrm{TM}$ and $\mathrm{R}-\mathrm{Fe}-\mathrm{C}$ ternary systems ( $\mathrm{M}=\mathrm{Mn}, \mathrm{Co}, \mathrm{Ni}$; $\mathrm{R}=\mathrm{La}, \mathrm{Ce})$ over the whole concentration and temperature ranges is relevant. Recently, the phase equilibria in the $\{\mathrm{La}, \mathrm{Ce}\}-\mathrm{Fe}-\mathrm{C}$ and $\mathrm{Ce}-\mathrm{Fe}-$ $\{\mathrm{Mn}, \mathrm{Co}, \mathrm{Ni}\}$ systems were investigated. ${ }^{[10-19]}$ We present herein the results of a study on the phase equilibria in the $\mathrm{La}-\mathrm{Fe}-\mathrm{Co}$ system.

\section{Literature Survey}

\subsection{Binary La-Fe System}

Only limited experimental information is available for the phase diagram of the La-Fe system. An abnormal shape of 
the liquidus was observed between 8 and 19 at. $\% \mathrm{La}^{[20]}$ and has been discussed in a number of papers ${ }^{[21-24]}$ in terms of the possible existence of a stable or metastable miscibility gap in the liquid.

Recently, an experimental investigation of the binary La-Fe system was carried out by Mardani et al. ${ }^{[10]}$ Our experimental observations did not confirm the presence of a stable miscibility gap in the liquid phase of the La-Fe system. The La-Fe system is of simple eutectic type with eutectic reaction $1 \rightleftarrows(\alpha \mathrm{Fe})+(\beta \mathrm{La})$ at $788^{\circ} \mathrm{C}$ and 88 at.\% La. In addition, there is a metatectic reaction $(\delta \mathrm{Fe}) \rightleftarrows \mathrm{L}+(\gamma \mathrm{Fe})$ at $1383{ }^{\circ} \mathrm{C}$ due to $(\delta \mathrm{Fe}) \rightleftarrows(\gamma \mathrm{Fe})$. The liquid phase in the metatectic reaction contains $\sim 50$ at. $\%$ La.

\subsection{Binary Fe-Co System}

The phase diagram of the $\mathrm{Fe}-\mathrm{Co}$ system adopted in the current work is according to Ohnuma et al. ${ }^{[25]}$ The following crystalline phases are formed in the system: $(\delta \mathrm{Fe})$ phase (high-temperature bcc solution based on iron), $(\alpha \mathrm{Co}, \gamma \mathrm{Fe})$-phase (fcc solution based on pure components), $(\alpha \mathrm{Fe})$-phase (low-temperature bcc solution based on iron), ordered cubic phase $\mathrm{FeCo}\left(\alpha^{\prime}\right)$ (B2 prototype of $\mathrm{CsCl}$ ), and $(\varepsilon \mathrm{Co})$-phase (hcp-solution based on cobalt). On the liquidus and solidus lines of the $(\alpha \mathrm{Co}, \gamma \mathrm{Fe})$ phase, a minimum is present.

The temperature of the $\gamma$ (fcc) $\rightarrow \alpha$ (bcc) transition increases with increasing Co concentration and reaches a maximum at $979{ }^{\circ} \mathrm{C}$ and 44 at. $\%$ Co. At $\sim 50$ at. $\%$ Co and $730{ }^{\circ} \mathrm{C}$, the bcc $\alpha \mathrm{Fe}$ phase is transformed into an ordered cubic structure B2 with CsCl-type structure $\left(\alpha^{\prime}\right)$. The solid solution $(\alpha \mathrm{Co}, \gamma \mathrm{Fe})$ at a temperature of $239{ }^{\circ} \mathrm{C}$ and 94.7 at.\% Co decomposes by eutectoid reaction into $\alpha^{\prime}(\mathrm{CoFe})+(\varepsilon \mathrm{Co})$.

\subsection{Binary La-Co System}

The phase diagram of the La-Co system adopted in this work is according to thermodynamic modeling by Wang et al., ${ }^{[26]}$ which generally agrees well with the experimental data of Buschow and Velge. ${ }^{[27]}$ The system is characterized by the presence of seven intermetallic compounds: $\mathrm{CoLa}_{3}, \mathrm{Co}_{1.7} \mathrm{La}_{2}, \mathrm{Co}_{3} \mathrm{La}_{2}, \mathrm{Co}_{7} \mathrm{La}_{2}, \mathrm{Co}_{19} \mathrm{La}_{5}, \mathrm{Co}_{5}$ $\mathrm{La}$, and $\mathrm{Co}_{13} \mathrm{La}$. Only the $\mathrm{CoLa}_{3}$ compound melts congruently, at a temperature of $543{ }^{\circ} \mathrm{C}$, while the remaining six compounds are formed by peritectic reactions at $570{ }^{\circ} \mathrm{C}, 695{ }^{\circ} \mathrm{C}, 800{ }^{\circ} \mathrm{C}, 868{ }^{\circ} \mathrm{C}, 1090{ }^{\circ} \mathrm{C}$, and $1185^{\circ} \mathrm{C}$, respectively. The $\mathrm{Co}_{7} \mathrm{La}_{2}$ compound exists in two polymorphic modifications; however, the transformation temperature is unknown.

The La-Co system also contains two eutectics: $\mathrm{L} \rightleftarrows \mathrm{Co}_{1.7} \mathrm{La}_{2}+\mathrm{CoLa}_{3}$ with coordinates $523{ }^{\circ} \mathrm{C}$ and
31.5 at.\% Co, and $\mathrm{L} \rightleftarrows \mathrm{Co}_{1.7} \mathrm{La}_{2}+\mathrm{CoLa}_{3}$ with coordinates $521{ }^{\circ} \mathrm{C}$ and 18.7 at.\% Co. ${ }^{[26]}$ However, note that the temperatures of these eutectics according to different authors differ significantly. Therefore, in this work, the temperature and composition of these eutectics were verified.

\subsection{Ternary La-Fe-Co System}

There is a lack of experimental data for the $\mathrm{La}-\mathrm{Fe}-\mathrm{Co}$ system. Kharchenko et al. ${ }^{[28]}$ investigated phase equilibria in the system at $800{ }^{\circ} \mathrm{C}$ (in the range up to 20 at. $\% \mathrm{La}$ ) and $400{ }^{\circ} \mathrm{C}$ (in the range from 20 to 100 at.\% La) using SEM and X-ray diffraction. The existence of the ternary compound $(\mathrm{Co}, \mathrm{Fe})_{17-x} \mathrm{La}_{2}\left(\mathrm{Th}_{2} \mathrm{Zn}_{17}\right.$-type structure, $R-3 m$, $a=8.524, c=12.37 \AA$ ) had been reported by Kharchenko et al. ${ }^{[28]}$ This compound has a homogeneity region of $17-22$ at.\% Fe. It was reported that the solubility of $\mathrm{Fe}$ in $\mathrm{Co}_{13} \mathrm{La}$ extends up to 30 at. $\%^{[28]}$ However, data about phase equilibria in the $\mathrm{La}-\mathrm{Fe}-\mathrm{Co}$ system during crystallization are completely absent, as well as information on the temperature and nature of the formation of the ternary compound.

\section{Experimental Methods}

\subsection{Sample Preparation}

The samples were melted from starting materials with purity of $\mathrm{Fe}-99.99 \%, \mathrm{Co}-99.9 \%$, and $\mathrm{La}-99.9 \%$ in an arc furnace with an inconsumable tungsten electrode on a water-cooled copper hearth in an Ar atmosphere purified by a Ti melt. The samples were remelted four or five times to ensure their chemical homogeneity. The weight loss was no more than $0.1 \%$. The ingot weight was $3 \mathrm{~g}$. The composition of each sample was analyzed by microprobe analysis, revealing good agreement with the composition of the initial alloy mixture.

To study equilibria at solidus temperature, after preparation, some of the samples were annealed at subsolidus temperatures. The annealing was performed in a tube furnace (Nabertherm RHTV 120/300/1700) with temperature accuracy of $\pm 3{ }^{\circ} \mathrm{C}$ in $\mathrm{Ar}$ atmosphere. The samples were placed in an $\mathrm{Al}_{2} \mathrm{O}_{3}$ crucible and additionally wrapped by a titanium lid to avoid oxidation. After annealing, some samples were quenched in oil to retain the equilibrium microstructures. On the whole, a few hours was sufficient to achieve equilibrium during annealing at subsolidus temperature. However prolonged annealing time was necessary for some samples. Annealing temperatures were selected to be $5-10{ }^{\circ} \mathrm{C}$ below $\left[T_{\text {ann }}=T_{\text {sol }}-\left(5-10{ }^{\circ} \mathrm{C}\right)\right]$ solidus temperatures determined from the DTA curves of 
the as-cast and annealed alloys. The annealing temperatures and times are summarized in Table 4.

\subsection{Microstructure Analysis}

Samples for microstructure analysis were prepared using a grinder and polisher (Struers Labopol-5) machine. Grinding was carried out with $\mathrm{SiC}$ paper and continued with polishing using diamond discs with grain size of 9,3 , and 1 microns, respectively. Diamond suspension was applied at regular intervals during the preparation.

The prepared samples were examined by optical microscopy (OM, Olympus-GX71F-5) and scanning electron microscopy (SEM) using a TESCAN VEGA LMH microscope with $\mathrm{a} \mathrm{LaB}_{6}$ cathode and an energy-dispersive $\mathrm{X}$-ray microanalysis system (Oxford Instruments Advanced AZtecEnergy). For analysis, both backscattered electron and secondary-electron imaging were used. A four-crystal wave spectrometer was used during the electron probe microanalysis (EPMA) of all the phases (analyzed particle size larger than $2 \mu \mathrm{m}$ ). The EPMA acceleration voltage was set at $20 \mathrm{kV}$. The measurement error in determining the concentration of elements using $\mathrm{X}$-ray analysis was $0.1 \mathrm{wt} . \%$.

\subsection{Differential Thermal Analysis}

A DSC LABSYS evo Setaram was used to measure the phase-transition temperatures of the alloys. For calibration, pure metal standards Sn (99.9995\%), Al (99.995\%), Ag (99.99\%), $\mathrm{Cu}$ (99.999\%), and $\mathrm{Ni}(99.99 \%)$ were used. DTA samples were placed in an $\mathrm{Al}_{2} \mathrm{O}_{3}$ crucible, and experiments were carried out under flow of argon with $99.998 \%$ purity on as-cast and annealed samples. The heating and cooling rate was 5 and $10{ }^{\circ} \mathrm{C} / \mathrm{min}$. The temperatures of the invariant reactions were determined from the onset. Data for phase-transition temperatures were taken from heating curves. The liquidus temperatures on heating were evaluated from the peak maximum, and those on cooling from the corresponding onset. Pronounced supercooling effects were not observed for the investigated alloys, and the liquidus temperatures for some alloys were therefore taken from the corresponding cooling curve since thermal effects are shown more clearly on cooling. At the end of the heating and cooling process, Calisto Processing software was used to obtain the DTA curves, which were later calibrated based on the equipment's calibration factor.

\subsection{X-Ray Diffraction Analysis}

X-ray diffraction (XRD) analysis was carried out to determine the phases present in the alloys, using $\mathrm{Cu} \mathrm{K}_{\alpha}$ filtered radiation on fine powder samples prepared by grinding in an agate mortar. XRD measurements were performed on a multipurpose X-ray diffractometer (BrukerAXS D8 Discover) and DRON-3.0 diffractometer (Bourevestnik, Inc., St. Petersburg, Russia). The lattice parameters were refined by the least-squares method. The phases were determined by comparing diffraction patterns with literature or patterns calculated using the PowderCell $^{[29]}$ and WINXPOW ${ }^{[30]}$ software packages. Both the PowderCell and WINXPOW software packages were used to calculate lattice parameters based on the least-squares method.

\section{Experimental Investigation}

\subsection{La-Co System}

The temperature of the peritectic reaction for the formation of compound $\mathrm{La}_{5} \mathrm{Co}_{19}, \quad \mathrm{~L}+\mathrm{LaCo}_{5} \rightleftarrows \mathrm{La}_{5} \mathrm{Co}_{19}$, was reported to be $868{ }^{\circ} \mathrm{C}$ by Wang et al. ${ }^{[26]}$ and Ray and Strnat, ${ }^{[1]}$ while this temperature was not observed by Buschow and Velge. ${ }^{[27]}$ Therefore, to verify the temperature of this reaction, 30La-70Co alloy was prepared. The microstructure of this as-cast sample is shown in Fig. 1(a) and (b). The solidification path of this alloy is rather complex: after primary crystallization of the $\mathrm{LaCo}_{5}$ phase (dark grains), the phases $\mathrm{La}_{5} \mathrm{Co}_{19}$ (dark-gray grains), $\mathrm{La}_{2} \mathrm{Co}_{7}$ (gray grains), $\mathrm{La}_{2} \mathrm{Co}_{3}$ (light-gray grains), and $\mathrm{La}_{2} \mathrm{Co}_{1.7}$ (white) form through a sequence of peritectic reactions. The DTA curve of this alloy upon heating up to $1150{ }^{\circ} \mathrm{C}$ is shown in Fig. 2, indicating five phase transformations. The cooling curve also shows these transformations with slight overcooling. The thermal effect at $854{ }^{\circ} \mathrm{C}$ corresponds to the peritectic reaction for the formation of $\mathrm{La}_{5} \mathrm{Co}_{19}$ phase $\left(\mathrm{L}+\mathrm{LaCo}_{5} \rightleftarrows \mathrm{La}_{5} \mathrm{Co}_{19}\right)$, being somewhat lower than proposed in literature. ${ }^{[26,31]}$ The thermal effect at $840{ }^{\circ} \mathrm{C}$ corresponds to the peritectic reaction $\mathrm{L}+\mathrm{La}_{5} \mathrm{Co}_{19} \rightleftarrows \mathrm{La}_{2} \mathrm{Co}_{7}$, which is significantly higher than proposed in literature. ${ }^{[26,27]}$ The thermal effect for the peritectic reaction $\mathrm{L}+\mathrm{La}_{2} \mathrm{Co}_{7} \rightleftarrows \mathrm{La}_{2} \mathrm{Co}_{3}$ was measured at $694{ }^{\circ} \mathrm{C}$, in good agreement with literature. ${ }^{[26,27]}$ The effect at $710^{\circ} \mathrm{C}$, which has not been previously observed, probably corresponds to the polymorphic transformation of the phase $\mathrm{La}_{2} \mathrm{Co}_{7}$.

There is some controversy concerning the composition of the eutectic reaction $\mathrm{L} \rightleftarrows \mathrm{La}_{3} \mathrm{Co}+\mathrm{La}_{2} \mathrm{Co}_{1.7}$. Verification of the temperature and composition of this eutectic was performed on an as-cast sample with composition 69La-31Co. The obtained results are presented in Table 1 and 2 and Fig. 1(c). The microstructure of this alloy (Fig. 2c) is completely eutectic $\left(\mathrm{La}_{3} \mathrm{Co}+\mathrm{La}_{2} \mathrm{Co}_{1.7}\right)$. The eutectic temperature was measured to be $514{ }^{\circ} \mathrm{C}$, higher than proposed in Ref. ${ }^{[27,32]}$ but lower than proposed by 


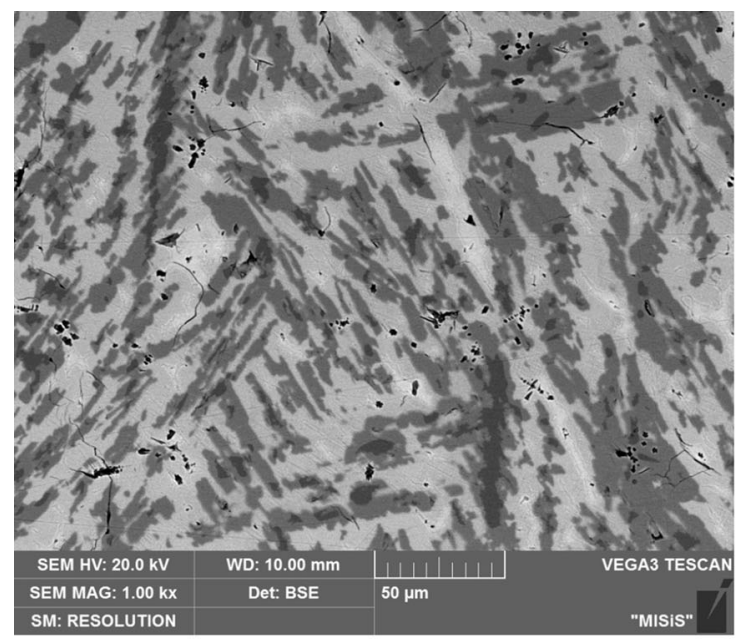

(a)

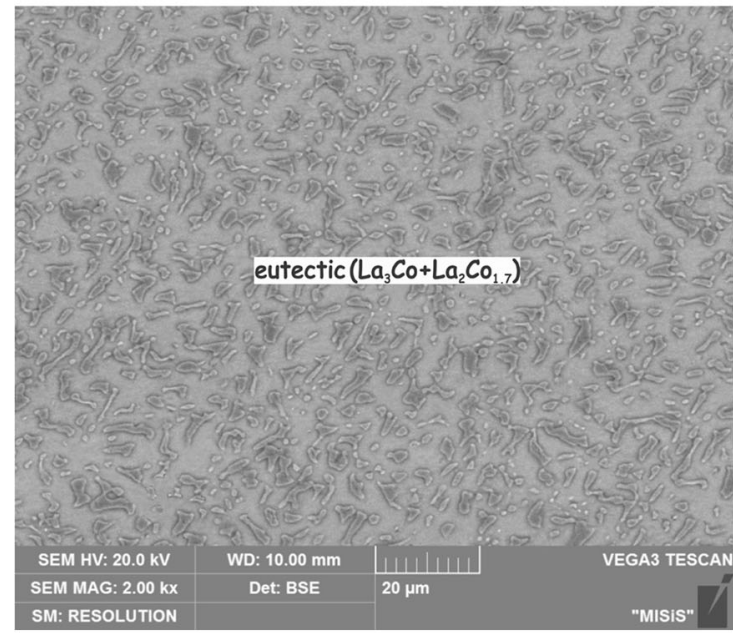

(c)

Fig. 1 Microstructure of as-cast alloys of La-Co system: a 30La$70 \mathrm{Co}, \times 1000, \mathrm{LaCo}_{5}+\mathrm{La}_{5} \mathrm{Co}_{19}+\mathrm{La}_{2} \mathrm{Co}_{7}+\mathrm{La}_{2} \mathrm{Co}_{3}+\mathrm{La}_{2} \mathrm{Co}_{1.7}$; b $30 \mathrm{La}-70 \mathrm{Co}, \times 2000, \mathrm{LaCo}_{5}+\mathrm{La}_{5} \mathrm{Co}_{19}+\mathrm{La}_{2} \mathrm{Co}_{7}+\mathrm{La}_{2} \mathrm{Co}_{3}+$

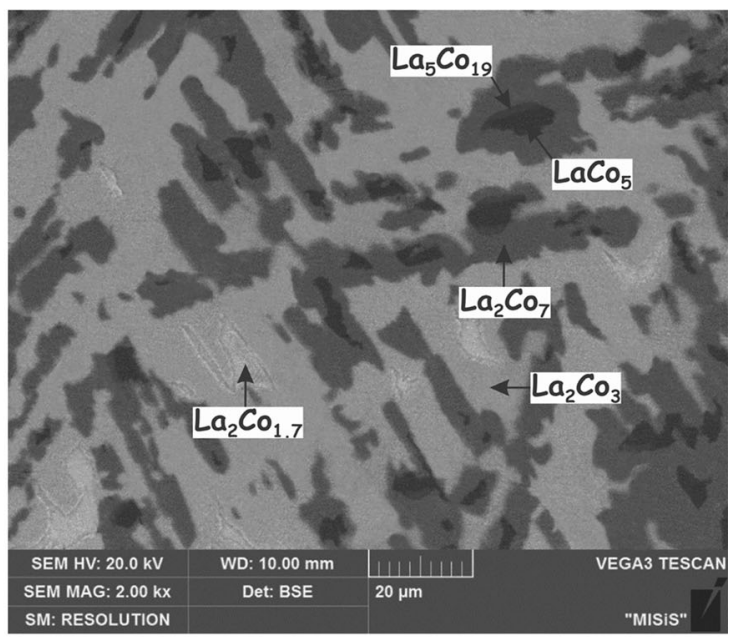

(b)

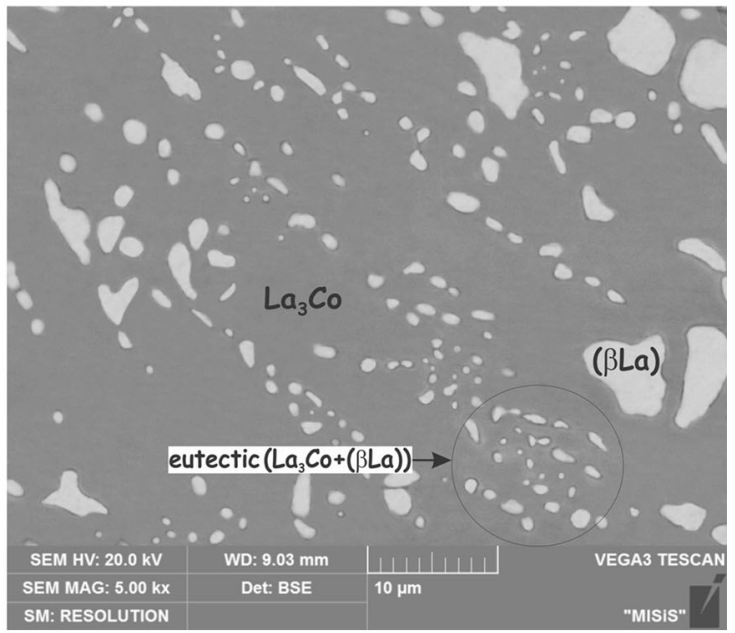

(d)

$\mathrm{La}_{2} \mathrm{Co}_{1.7} ;$ c $69 \mathrm{La}-31 \mathrm{Co}, \times 2000$, eutectic $\left(\mathrm{La}_{2} \mathrm{Co}_{1.7}+\mathrm{La}_{3} \mathrm{Co}\right)$; d $80 \mathrm{La}-20 \mathrm{Co}, \times 5000,(\beta \mathrm{La})+\mathrm{La}_{3} \mathrm{Co}+$ eutectic $\left((\beta \mathrm{La})+\mathrm{La}_{3} \mathrm{Co}\right)$

Fig. 2 Heating curve for ascast alloy 30La-70Co

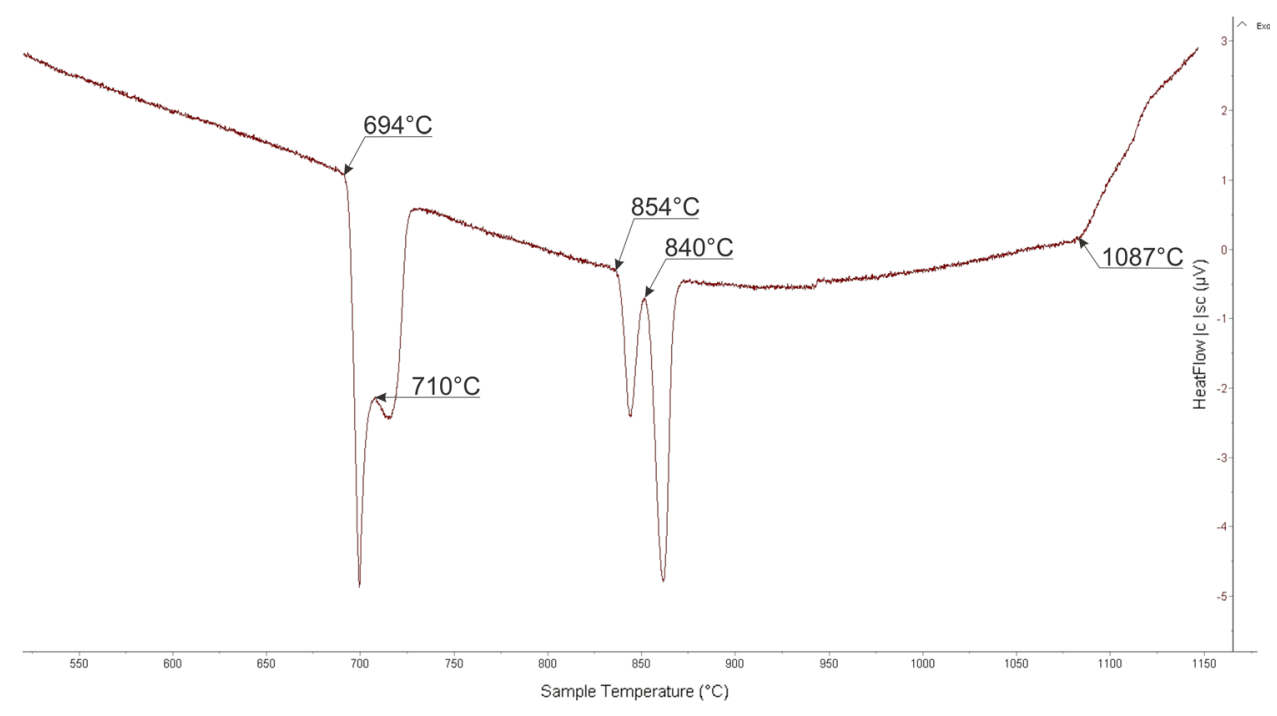


Table 1 Phase composition of alloys of La-Co system and temperature of phase transformations during crystallization

\begin{tabular}{|c|c|c|c|c|c|}
\hline \multicolumn{2}{|c|}{ Alloy, at.\% } & \multicolumn{2}{|c|}{ Temperature, ${ }^{\circ} \mathrm{C}$} & \multirow[t]{2}{*}{ Solidification path } & \multirow[t]{2}{*}{ Phase composition at solidus } \\
\hline $\mathrm{La}$ & $\mathrm{Co}$ & Liquidus & Solidus & & \\
\hline 30 & 70 & 1087 & 694 & $\mathrm{~L} \rightarrow \mathrm{LaCo}_{5}^{\mathrm{a}} \rightarrow \mathrm{La}_{5} \mathrm{Co}_{19} \rightarrow \mathrm{La}_{2} \mathrm{Co}_{7} \rightarrow \mathrm{La}_{2} \mathrm{Co}_{3} \rightarrow \mathrm{La}_{2} \mathrm{Co}_{1.7}$ & $\mathrm{La}_{2} \mathrm{Co}_{7}+\mathrm{La}_{2} \mathrm{Co}_{3}$ \\
\hline 69 & 31 & - & 514 & $\mathrm{~L} \rightarrow$ eutectic $\left(\mathrm{La}_{2} \mathrm{Co}_{1.7}+\mathrm{La}_{3} \mathrm{Co}\right)$ & $\mathrm{La}_{2} \mathrm{Co}_{1.7}+\mathrm{La}_{3} \mathrm{Co}$ \\
\hline 80 & 20 & 559 & 530 & $\mathrm{~L} \rightarrow(\boldsymbol{\beta L a}) \rightarrow \mathrm{La}_{3} \mathrm{Co} \rightarrow$ eutectic $\left((\beta \mathrm{La})+\mathrm{La}_{3} \mathrm{Co}\right)$ & $(\beta \mathrm{La})+\mathrm{La}_{3} \mathrm{Co}$ \\
\hline 90 & 10 & 756 & 530 & $\mathrm{~L} \rightarrow(\boldsymbol{\beta L a}) \rightarrow \mathrm{La}_{3} \mathrm{Co} \rightarrow$ eutectic $\left((\beta \mathrm{La})+\mathrm{La}_{3} \mathrm{Co}\right)$ & $(\beta \mathrm{La})+\mathrm{La}_{3} \mathrm{Co}$ \\
\hline
\end{tabular}

${ }^{\text {a } B o l d ~ s h o w s ~ t h e ~ p r i m a r y ~ p h a s e ~}$

Table 2 Chemical composition of phases of as-cast alloys of La-Co system according to EMPA

\begin{tabular}{|c|c|c|c|c|c|c|}
\hline \multicolumn{4}{|c|}{ Alloy composition, at.\% } & \multicolumn{3}{|c|}{ EPMA data, at. $\%$} \\
\hline \multicolumn{2}{|c|}{ Nominal } & \multicolumn{2}{|c|}{ Measured } & \multirow[t]{2}{*}{ Phase } & \multirow[t]{2}{*}{$\mathrm{La}$} & \multirow[t]{2}{*}{$\mathrm{Co}$} \\
\hline $\mathrm{La}$ & Co & $\mathrm{La}$ & Co & & & \\
\hline \multirow[t]{4}{*}{30} & 70 & 30.9 & 69.1 & $\mathrm{LaCo}_{5}$ & $82.6 \pm 0.1$ & $17.4 \pm 0.1$ \\
\hline & & & & $\mathrm{La}_{2} \mathrm{Co}_{7}$ & $77.0 \pm 0.1$ & $23.0 \pm 0.1$ \\
\hline & & & & $\mathrm{La}_{2} \mathrm{Co}_{3}$ & $59.5 \pm 0.1$ & $40.5 \pm 0.1$ \\
\hline & & & & $\mathrm{La}_{2} \mathrm{Co}_{1.7}$ & $47.1 \pm 0.3$ & $52.9 \pm 0.3$ \\
\hline \multirow[t]{2}{*}{69} & 31 & 69.5 & 30.5 & eutectic & 69.4 & 30.6 \\
\hline & & & & $\left(\mathrm{La}_{2} \mathrm{Co}_{1.7}+\mathrm{La}_{3} \mathrm{Co}\right)$ & 69.5 & 30.5 \\
\hline \multirow[t]{5}{*}{80} & 20 & 19.7 & 80.3 & $(\beta \mathrm{La})$ & $0.0 \pm 0.0$ & $100.0 \pm 0.0$ \\
\hline & & & & $\mathrm{La}_{3} \mathrm{Co}$ & $23.8 \pm 0.2$ & $76.2 \pm 0.2$ \\
\hline & & & & eutectic & 19.8 & 80.2 \\
\hline & & & & $\left((\beta \mathrm{La})+\mathrm{La}_{3} \mathrm{Co}\right)$ & 20.3 & 79.7 \\
\hline & & & & & 19.4 & 80.6 \\
\hline
\end{tabular}

Wang et al. ${ }^{[26]}$ The eutectic composition according to EPMA data was 30.5 at.\% Co, in good agreement with Buschow and Velge. ${ }^{[27]}$

Verification of the temperature and composition for the eutectic $\mathrm{L} \rightleftarrows(\beta \mathrm{La})+\mathrm{La}_{3} \mathrm{Co}$ was performed on as-cast samples 10La-90Co and 20La-80Co. The results obtained are presented in Table 1 and Fig. 1(d). The microstructure of this alloy (Fig. 1d) shows the primary ( $\beta$ La)-phase and the eutectic $\left((\beta \mathrm{La})+\mathrm{La}_{3} \mathrm{Co}\right)$. The composition of this eutectic was established by the microprobe method as 19.8 at.\% Co, in good agreement with Ref. [27,32]. The eutectic temperature was measured to be $530{ }^{\circ} \mathrm{C}$, slightly higher than proposed in Ref. [26,27,32]. The revised phase diagram of the La-Co system is shown in Fig. 3.

\subsection{La-Fe-Co System}

The phase equilibria in the $\mathrm{La}-\mathrm{Fe}-\mathrm{Co}$ system were investigated during solidification. The resulting liquidus (Fig. 4a) and solidus projections (Fig. 4b) and the melting diagram (Fig. 4c) of the La-Fe-Co system have been constructed over the whole concentration range. The phase compositions of the studied alloys and chemical compositions of the phases of the La-Fe-Co system according to the EPMA results are reported in Table 3 and 4 , respectively. Table 3 also presents the liquidus and solidus temperatures of the investigated alloys. The compositions of the investigated alloys in Fig. 4 correspond to measured compositions of alloys, whereas in Table 3 nominal compositions are given, and in Table 4 both nominal and measured compositions are given. The microstructures of some as-cast and annealed samples are shown in Fig. 5 and 6, respectively. The XRD patterns of some as-cast alloys are shown in Fig. 7. The crystal structure and lattice parameters of the phases of the $\mathrm{Fe}-$ Co-La system are presented in Table 5.

\subsubsection{Ternary Compound $(\mathrm{Co}, \mathrm{Fe})_{17} \mathrm{La}_{2}(\tau)$}

The existence of the ternary compound $(\mathrm{Co}, \mathrm{Fe})_{17} \mathrm{La}_{2}(\tau)$ (structure type $\mathrm{Th}_{2} \mathrm{Zn}_{17}, R-3 m$ ), which was previously reported, ${ }^{[28,33,34]}$ was confirmed in our study. It was shown that ternary compound $\tau$ forms by peritectic reaction $\mathrm{L}_{\mathrm{P} 1}+\mathrm{LaCo}_{13}+\mathrm{LaCo}_{5} \rightleftarrows \tau$ at $978{ }^{\circ} \mathrm{C}$ and has a wide homogeneity range from 45.8 to 79.5 at.\% Co located along the isoconcentrate of $\sim 11$ at.\% La. This somewhat 
Fig. 3 Revised phase diagram of La-Co system: open triangles-DTA data

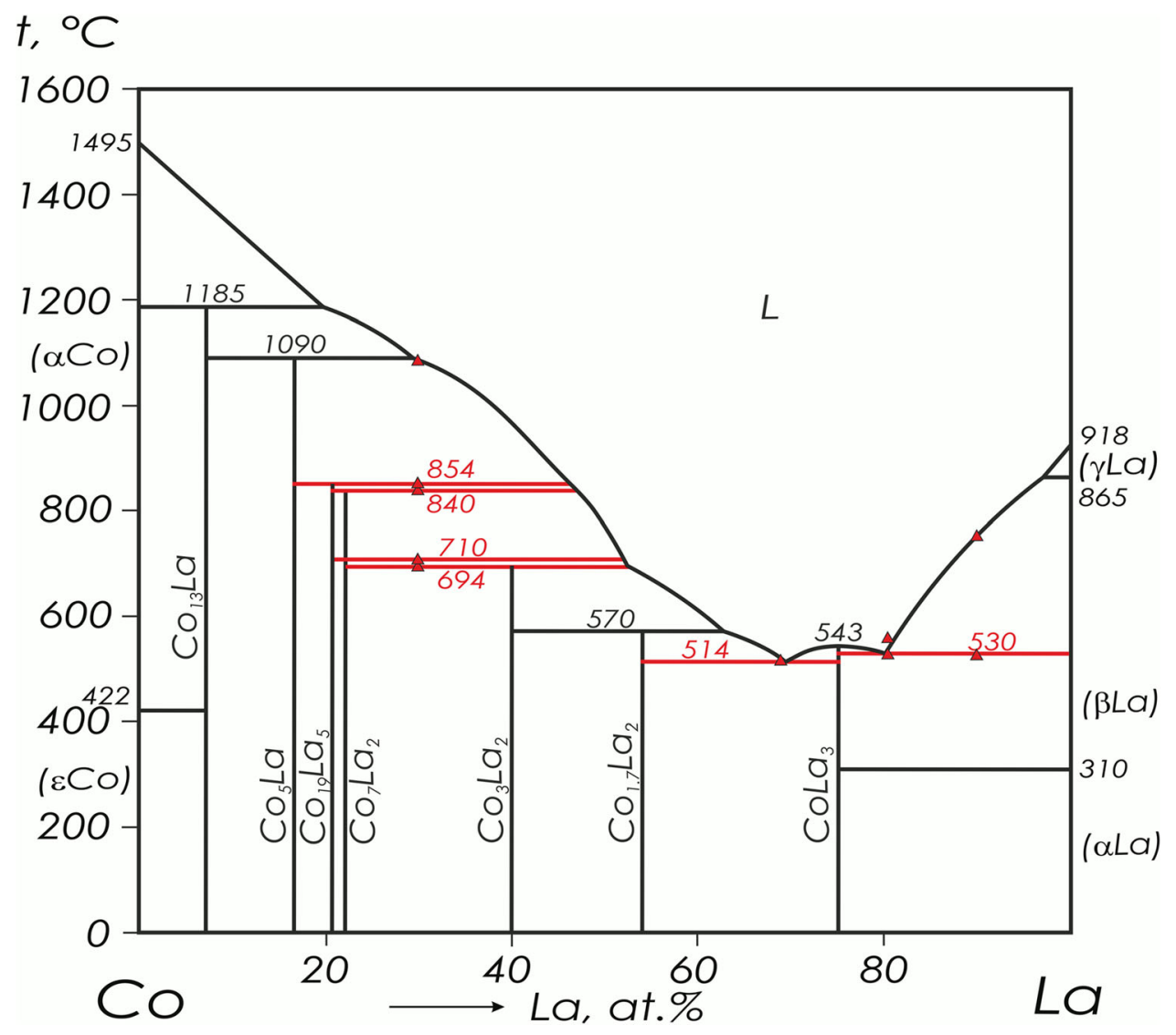

contradicts the data of Kharchenko et al., ${ }^{[28]}$ who reported that the homogeneity region of the $\tau$ phase is located along the isoconcentrate of 15 at.\% La. The iron-rich boundary of the region of homogeneity of the $\tau$ phase is defined as 45.8 at.\% Co according to the EPMA data of alloy \#1 (Fig. 5a, Table 4). The homogeneity region of the cobaltrich side $\tau$ phase is defined as 79.5 at.\% Co according to the EPMA data of alloy \# 2 (Table 4).

\subsubsection{Solid Phases}

In addition to the ternary compound $(\mathrm{Co}, \mathrm{Fe})_{17} \mathrm{La}_{2}(\tau)$ in the $\mathrm{La}-\mathrm{Co}-\mathrm{Fe}$ system, other phases based on the binary compounds $\mathrm{Co}_{13} \mathrm{La}, \mathrm{Co}_{5} \mathrm{La}, \mathrm{Co}_{19} \mathrm{La}_{5}, \mathrm{Co}_{7} \mathrm{La}_{2}, \mathrm{Co}_{3} \mathrm{La}_{2}, \mathrm{Co}_{1.7}$ $\mathrm{La}_{2}$, and $\mathrm{CoLa}_{3}$ and components $(\delta \mathrm{Fe}),(\gamma \mathrm{Co}, \mathrm{Fe}),(\alpha \mathrm{Co}, \mathrm{Fe})$, $(\gamma \mathrm{La})$, and $(\beta \mathrm{La})$ take part in phase equilibria.

Among the binary compounds, $\mathrm{Co}_{13} \mathrm{La}$ (structural type $\mathrm{NaZn}_{13}, c F 112-F m-3 c$ ) has the widest homogeneity region at solidus temperature and, according to EPMA data of ascast alloys \#3 and \#4 (Table 4), dissolves up to 43.3 at.\% Fe. The homogeneity region of this phase is located along the isoconcentrate of 7 at.\% La and extends widely into a ternary system, which reflects significant mutual substitution of $\mathrm{Co}$ and $\mathrm{Fe}$ atoms. The lattice parameter $a$ of $\mathrm{Co}_{13} \mathrm{La}$ phase gradually increases with increasing $\mathrm{Fe}$ content (Table 5).

According to the EPMA data of as-cast alloy \#5, the solubility of $\mathrm{Fe}$ in $\mathrm{Co}_{5} \mathrm{La}$ is 10.3 at.\% (Table 4). The solubility of $\mathrm{Fe}$ in $\mathrm{Co}_{7} \mathrm{La}_{2}$ at solidus temperature reaches 9.2 at. \% according to the EPMA data of cast alloy \#6. The homogeneity regions of the remaining phases are smaller. The solubility of $\mathrm{Fe}$ in the $\mathrm{Co}_{19} \mathrm{La}_{5}$ phase at solidus temperature is 4.7 at.\% according to the EPMA data of alloy \#7 annealed at subsolidus temperature $\left(810^{\circ} \mathrm{C}, 4 \mathrm{~h}\right)$. The solubility of $\mathrm{Fe}$ in $\mathrm{Co}_{3} \mathrm{La}_{2}$ is even less and amounts to 3.2 at.\% at solidus temperature. The solubility of $\mathrm{Fe}$ in $\mathrm{Co}_{1.7} \mathrm{La}_{2}$ and $\mathrm{CoLa}_{3}$ according to EPMA does not exceed 1 at.\%. The maximum solubility of $\mathrm{La}$ in $(\gamma \mathrm{Co}, \mathrm{Fe})$ and $(\alpha \mathrm{Co}, \mathrm{Fe})$ phases is determined to be less than 1 at.\% (Table 4).

\subsubsection{Liquidus Projection}

The liquidus surface of the Fe-La-Co system (Fig. 4a) is characterized by the 13 primary solidification fields of the ternary compound $(\mathrm{Co}, \mathrm{Fe})_{17} \mathrm{La}_{2}(\tau)$, solid solutions based on binary phases $\mathrm{Co}_{13} \mathrm{La}, \mathrm{Co}_{5} \mathrm{La}, \mathrm{Co}_{19} \mathrm{La}_{5}, \mathrm{Co}_{7} \mathrm{La}_{2}, \mathrm{Co}_{3}$ $\mathrm{La}_{2}, \mathrm{Co}_{1.7} \mathrm{La}_{2}$, and $\mathrm{CoLa}_{3}$, and component-based solid solutions $(\delta \mathrm{Fe}),(\gamma \mathrm{Co}, \mathrm{Fe}),(\alpha \mathrm{Co}, \mathrm{Fe}),(\gamma \mathrm{La})$, and $(\beta \mathrm{La})$, 
Fig. 4 Liquidus (a) and solidus (b) projections and the melting diagram (c) of the $\mathrm{La}-\mathrm{Co}-\mathrm{Fe}$ system: open circlecomposition of sample, dotted circle-two-phase sample, filled circle-three-phase sample, open and filled triangle-EPMA data for as-cast and annealed alloys, respectively

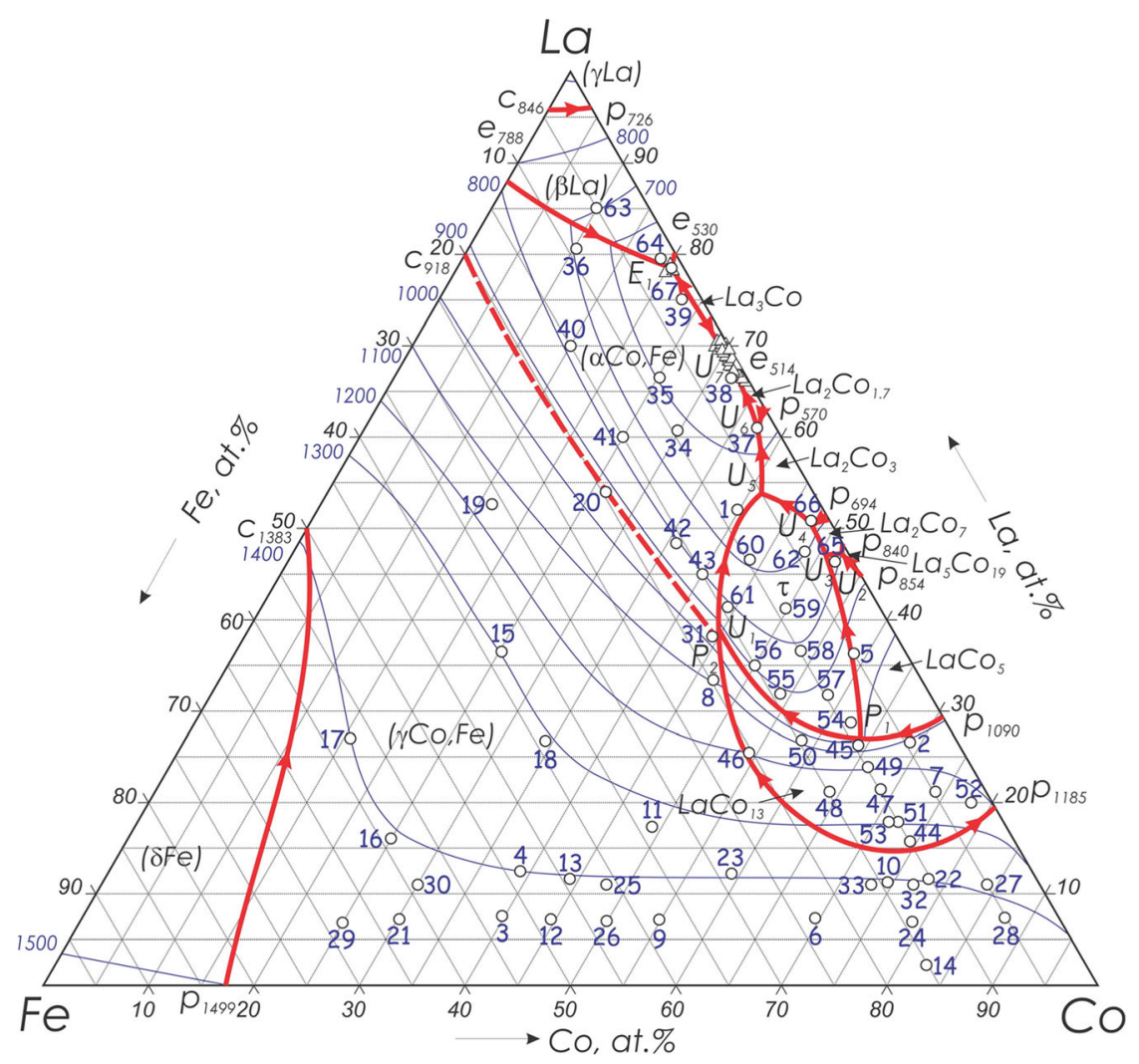

(a)

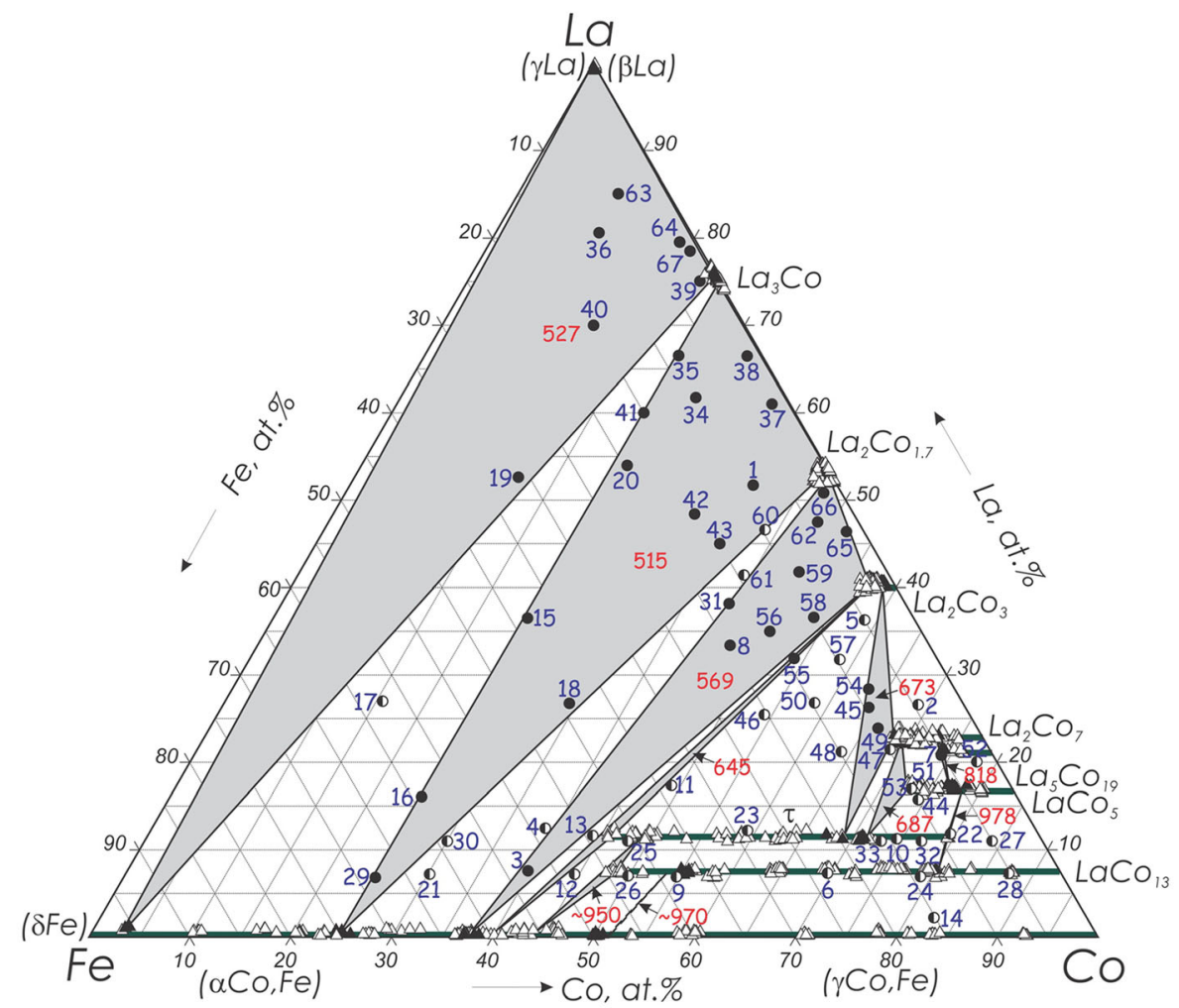

(b) 
Fig. 4 continued

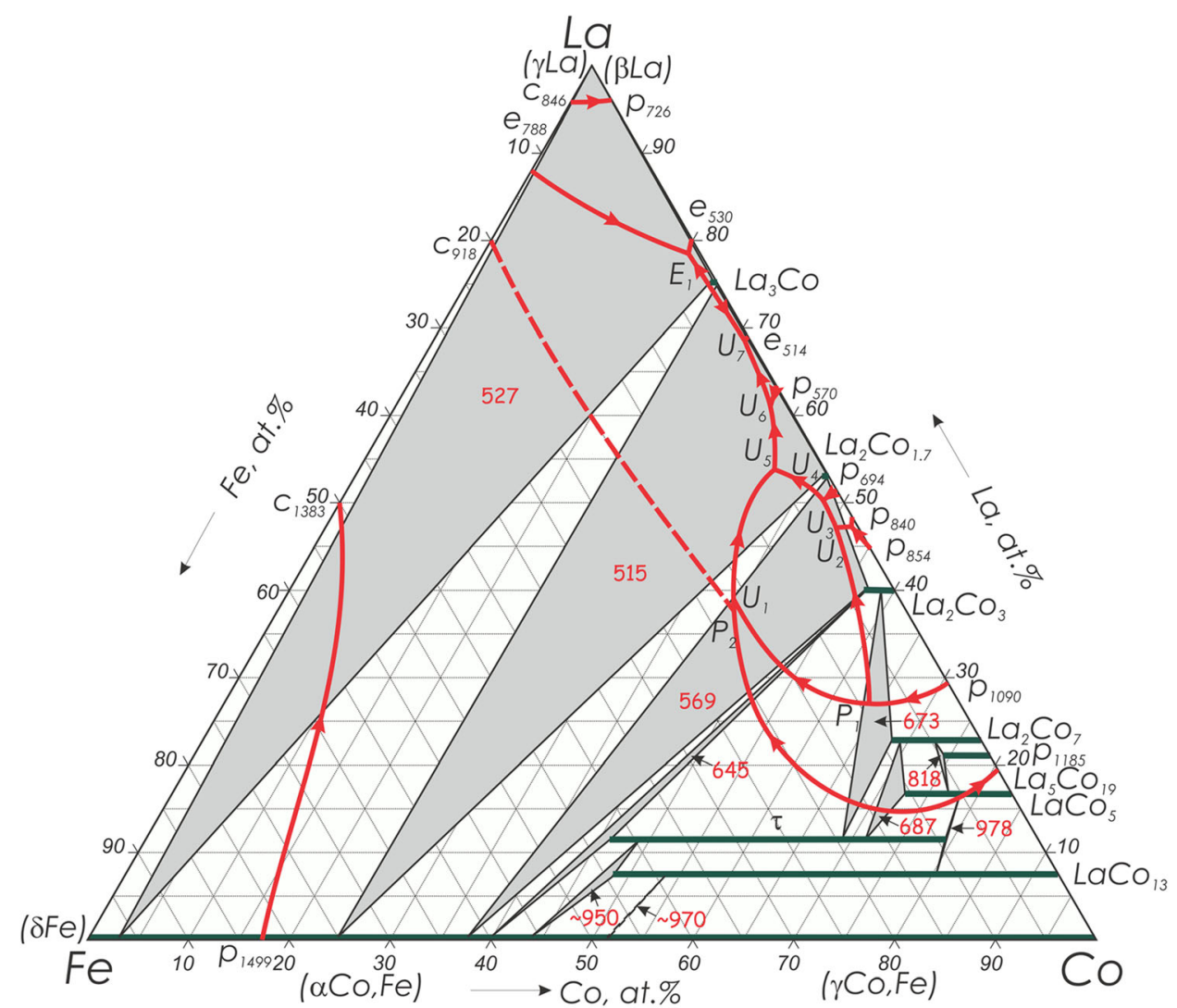

(c)

separated by appropriate monovariant curves and participating in ten four-phase invariant equilibria. One fourphase invariant equilibrium is of eutectic type, two are of peritectic type, the the rest are of transitional type.

The primary solidification field of the $(\gamma \mathrm{Co}, \mathrm{Fe})$-phase occupies the major part of the liquidus (Fig. 4a). Analysis of the microstructures of the as-cast samples showed that the compositions of most of the investigated alloys (\#3, 4, $6,8-33)$ are located in the primary solidification field of the $(\gamma \mathrm{Co}, \mathrm{Fe})$ phase. Typical microstructures of alloys from this region are shown in Fig. 5(b) and (c). The solidification of alloy \#8 begins with formation of the $(\gamma \mathrm{Co}, \mathrm{Fe})$-phase (black grains), continues with the formation of $\tau$ phase (gray grains) around the primary grains, then phases $\mathrm{Co}_{3}$ $\mathrm{La}_{2}$ (light-gray grains) and $\mathrm{Co}_{1.7} \mathrm{La}_{2}$ (light grains) are formed, and the solidification finishes with eutectic reaction $\left(\mathrm{Co}_{17} \mathrm{La}_{2}+\mathrm{CoLa}_{3}\right)$ (Fig. 5b). For alloy $\# 10$, the crystallization path is also rather complex: after the primary crystallization of the $(\gamma \mathrm{Co}, \mathrm{Fe})$ phase (black grains), the phases $\mathrm{Co}_{13} \mathrm{La}$ (dark-gray grains), $\mathrm{Co}_{5} \mathrm{La}$ (gray grains), $\mathrm{Co}_{7} \mathrm{La}_{2}$ (light-gray grains), and $\mathrm{Co}_{3} \mathrm{La}_{2}$ (light grains) crystallize by peritectic reactions (Fig. 5c).
Alloys \#1, 34-43 are located in the field of primary crystallization of the $(\alpha \mathrm{Co}, \mathrm{Fe})$ phase (Fig. $5 \mathrm{a}, \mathrm{d}, \mathrm{e})$. The border of this field is limited by the composition of alloys \#1, 36-39, in which only a small amount of primary grains of $(\alpha \mathrm{Co}, \mathrm{Fe})$ phase are observed (Fig. $5 \mathrm{a}, \mathrm{d}, \mathrm{e})$.

Alloys \#2, 7, 44-53 are located in the field of primary crystallization of the $\mathrm{Co}_{13} \mathrm{La}$ phase (Fig. $5 \mathrm{f}-\mathrm{i}$ ). The observation of primary $(\gamma \mathrm{Co}, \mathrm{Fe})$ in sample \#8 (Fig. $5 \mathrm{~b})$ in contrast to primary $\mathrm{Co}_{13} \mathrm{La}$ in samples \#44 and \#46 (Fig. 5f, g) indicates that the monovariant curve $\mathrm{L}+(\gamma \mathrm{Co}, \mathrm{Fe}) \rightleftarrows \mathrm{Co}_{13} \mathrm{La}$ of joint crystallization of the phases $(\gamma \mathrm{Co}, \mathrm{Fe})$ and $\mathrm{Co}_{13} \mathrm{La}$ is located between the compositions of these alloys. Note that the monovariant curve $\mathrm{L}+(\gamma \mathrm{Co}, \mathrm{Fe}) \rightleftarrows \mathrm{Co}_{13} \mathrm{La}$ has a saddle point corresponding to the maximum temperature on the solidus surface $(\gamma \mathrm{Co}, \mathrm{Fe})+\mathrm{Co}_{13} \mathrm{La}$ at $\sim 1300{ }^{\circ} \mathrm{C}$.

The location of the monovariant curve $P_{1} U_{1}$, separating the fields of primary solidification of $\mathrm{Co}_{13} \mathrm{La}$ and $\tau$, is evident from the observation of the primary $\mathrm{Co}_{13} \mathrm{La}$ in samples \#45 and \#50 (Fig. 5g) in contrast to $\tau$-phase in samples \#54-56. Some attention should be focused on the microstructure of samples \#45 and \#50 (Fig. 5g), where questions arise regarding whether the primary solidified 


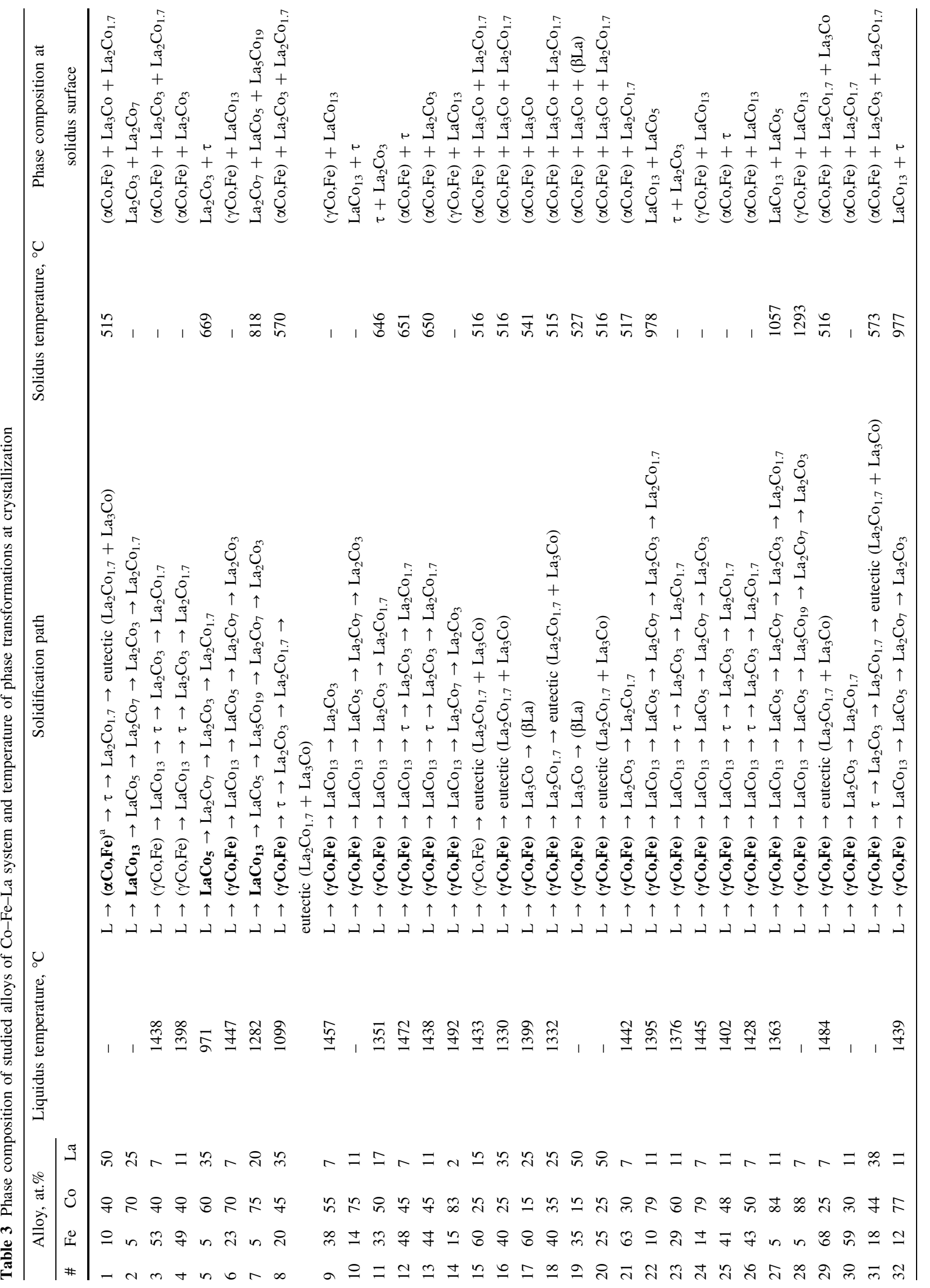




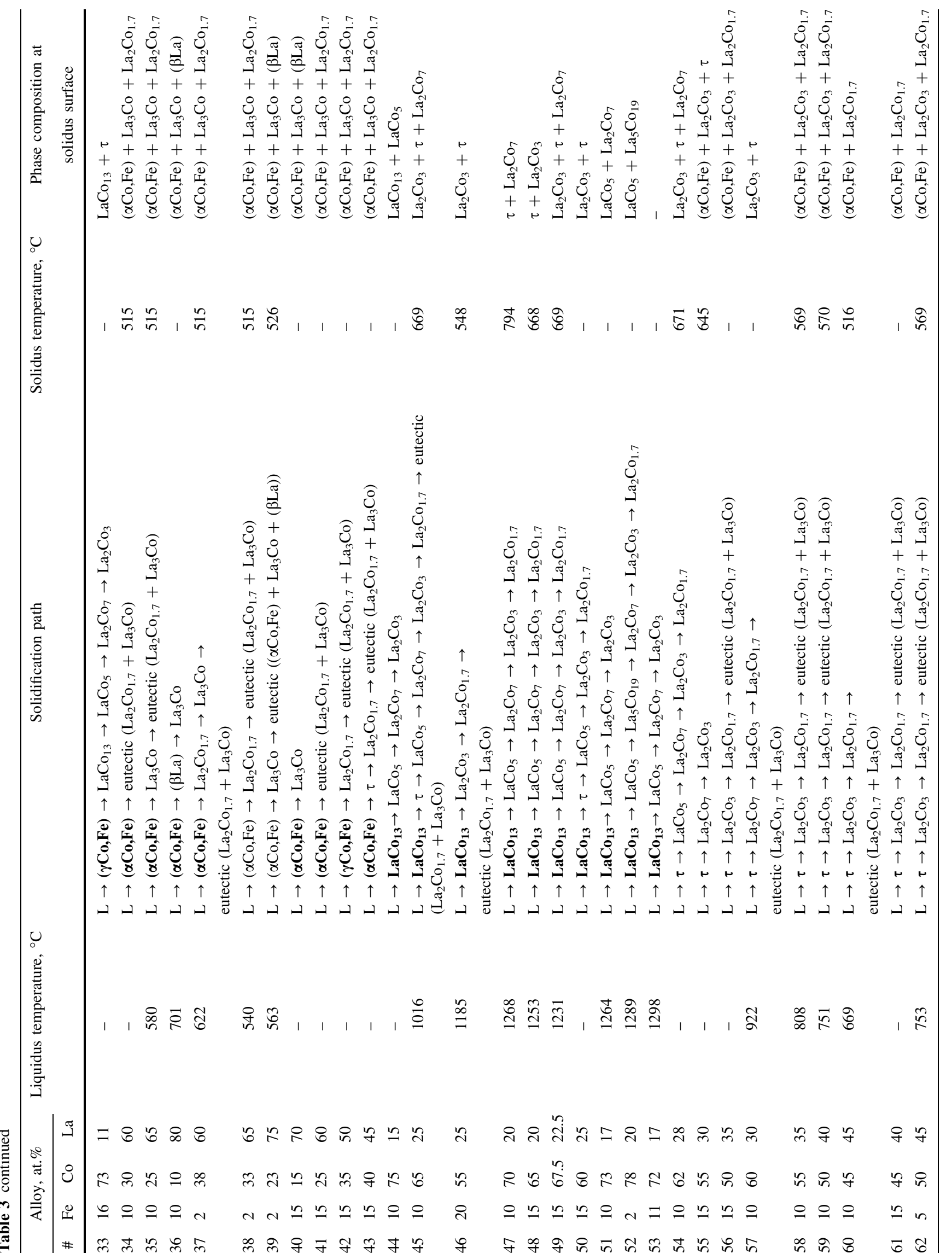


phase is $\mathrm{Co}_{13} \mathrm{La}$ phase (black grains) or $\tau$ phase (dark-gray grains). Both $\mathrm{Co}_{13} \mathrm{La}$ and $\tau$ appear primary. Possibly, the primary phase in these alloys is the $\mathrm{Co}_{13} \mathrm{La}$ phase, then after primary crystallization of $\mathrm{Co}_{13} \mathrm{La}$, the liquid becomes depleted of lanthanum, and the $\tau$ phase crystallizes as primary, as well. This indicates that these alloys are located almost on a monovariant curve $\mathrm{L}+\mathrm{Co}_{13} \mathrm{La} \rightleftarrows \tau$. In alloy \#45, after crystallization of the $\mathrm{Co}_{13} \mathrm{La}$ phase (black grains) and $\tau$ phase (dark-gray grains), the phases $\mathrm{LaCo}_{5}, \mathrm{La}_{2} \mathrm{Co}_{7}$, and $\mathrm{La}_{2} \mathrm{Co}_{3}$ crystallize. Solidification finishes with the formation of the eutectic $\left(\mathrm{La}_{2} \mathrm{Co}_{1.7}\right.$ $+\mathrm{CoLa}_{3}$ ) (Fig. 5g).

Alloys \#54-62 are located in the field of primary crystallization of the $\tau$-phase (Fig. $5 \mathrm{j}$ ). The relative position of both monovariant curves and the composition of the ternary compound allow us to conclude that the compound melts incongruently. The incongruent formation of the $\tau$ phase is also confirmed by the nature of crystallization and liquidus temperature of the alloys in this composition range.

In alloy \#1, which is shown in Fig. 5(a), the primary grains of the $(\alpha \mathrm{Co}, \mathrm{Fe})$-phase with a typical cubic shape (black) are clearly visible, then the $\tau$ phases (dark gray) crystallize in this alloy and also appear primary. This indicates that this alloy is located very close to the monovariant curve of joint crystallization of the phases $\tau$ and $(\alpha \mathrm{Co}, \mathrm{Fe})$. The solidification in this alloy continues with the formation of the $\mathrm{Co}_{1.7} \mathrm{La}_{2}$ phase (gray grains) and finishes with the formation of the eutectic $\left(\mathrm{Co}_{1.7} \mathrm{La}_{2}\right.$ $+\mathrm{CoLa}_{3}$ ) (Fig. 5a).

In the La-rich corner and along the Co-La side, the fields of primary crystallization of phases based on the components $(\beta \mathrm{La})$ and $(\gamma \mathrm{La})$ and phases based on binary compounds $\mathrm{Co}_{19} \mathrm{La}_{5}, \mathrm{Co}_{7} \mathrm{La}_{2}, \mathrm{Co}_{3} \mathrm{La}_{2}, \mathrm{Co}_{1.7} \mathrm{La}_{2}$, and $\mathrm{CoLa}_{3}$ are present. They are all very narrow. The field $(\beta \mathrm{La})$ is plotted by observation of the primary ( $\beta \mathrm{La})$ phase in alloys \#63 and \#64 in contrast to the primary $(\alpha \mathrm{Co}, \mathrm{Fe})$-phase in alloy \#36. The field of $(\gamma \mathrm{La})$, as well as $(\delta \mathrm{Fe})$, is shown tentatively.

The boundaries of the fields of primary crystallization of phases based on cobalt lanthanides $\mathrm{Co}_{19} \mathrm{La}_{5}, \mathrm{Co}_{7} \mathrm{La}_{2}$, $\mathrm{Co}_{3} \mathrm{La}_{2}, \mathrm{Co}_{1.7} \mathrm{La}_{2}$, and $\mathrm{CoLa}_{3}$ are determined mainly from the microstructure of the alloys located along the isoconcentrate 2 at. $\% \mathrm{Fe}$. The field of primary crystallization of the $\mathrm{Co}_{5} \mathrm{La}$ phase is determined from the microstructure of alloys \#5 and \#65 (Fig. 5k), which shows that these alloys are located in the field of primary crystallization of the $\mathrm{Co}_{5} \mathrm{La}$ phase. Moreover, the microstructure of alloy \#65 contains a small amount of primary grains of the $\mathrm{Co}_{5} \mathrm{La}$ (black grains). After the primary crystallization of $\mathrm{Co}_{5} \mathrm{La}$ (black grains), the $\mathrm{Co}_{7} \mathrm{La}_{2}$ phase (dark-gray grains) forms around the primary grains, then the $\mathrm{Co}_{7} \mathrm{La}_{2}, \mathrm{Co}_{3} \mathrm{La}_{2}$, and $\mathrm{Co}_{1.7} \mathrm{La}_{2}$ phases crystallize (Fig. 5k). The location of the 
Table 4 Composition of Co-Fe-La phases according to EPMA data

\begin{tabular}{|c|c|c|c|c|c|c|c|c|c|c|c|}
\hline \multirow[t]{3}{*}{ \# } & \multicolumn{6}{|c|}{ Phase composition, at. $\%$} & \multirow[t]{3}{*}{ Heat treatment } & \multicolumn{4}{|c|}{ EPMA data, at.\% } \\
\hline & \multicolumn{3}{|c|}{ Nominal } & \multicolumn{3}{|c|}{ Measured } & & & & & \\
\hline & $\mathrm{Fe}$ & Co & $\mathrm{La}$ & $\mathrm{Fe}$ & Co & $\mathrm{La}$ & & Phase & $\mathrm{Fe}$ & Co & $\mathrm{La}$ \\
\hline \multirow[t]{7}{*}{1} & 10 & 40 & 50 & 7.9 & 39.9 & 52.2 & as-cast & $\tau$ & $42.4 \pm 0.3$ & $45.8 \pm 0.3$ & $11.8 \pm 0.2$ \\
\hline & & & & & & & & $\mathrm{La}_{2} \mathrm{Co}_{1.7}$ & $0.5 \pm 0.1$ & $45.9 \pm 0.3$ & $53.6 \pm 0.3$ \\
\hline & & & & & & & & $\mathrm{La}_{3} \mathrm{Co}$ & $0.0 \pm 0.1$ & $25.1 \pm 0.8$ & $74.9 \pm 0.8$ \\
\hline & & & & & & & & eutectic $\left(\mathrm{La}_{2} \mathrm{Co}_{1.7}+\mathrm{La}_{3} \mathrm{Co}\right)$ & 0.3 & 30.8 & 68.9 \\
\hline & & & & 8.2 & 40.0 & 51.8 & $510{ }^{\circ} \mathrm{C}, 1 \mathrm{~h}$ & $(\alpha \mathrm{Co}, \mathrm{Fe})$ & $74.1 \pm 0.4$ & $25.0 \pm 0.5$ & $0.9 \pm 0.2$ \\
\hline & & & & & & & & $\mathrm{La}_{2} \mathrm{Co}_{1.7}$ & $0.0 \pm 0.0$ & $46.5 \pm 0.1$ & $53.5 \pm 0.1$ \\
\hline & & & & & & & & $\mathrm{La}_{3} \mathrm{Co}$ & $0.0 \pm 0.0$ & $25.0 \pm 0.1$ & $75.0 \pm 0.1$ \\
\hline \multirow[t]{4}{*}{2} & 5 & 70 & 25 & 4.5 & 68.9 & 26.6 & as-cast & $\tau$ & $9.1 \pm 0.1$ & $79.4 \pm 0.1$ & $11.5 \pm 0.1$ \\
\hline & & & & & & & & $\mathrm{LaCo}_{5}$ & $5.9 \pm 0.1$ & $77.1 \pm 0.1$ & $17.0 \pm 0.2$ \\
\hline & & & & & & & & $\mathrm{La}_{2} \mathrm{Co}_{7}$ & $4.7 \pm 0.3$ & $72.2 \pm 0.4$ & $23.1 \pm 0.3$ \\
\hline & & & & & & & & $\mathrm{La}_{2} \mathrm{Co}_{3}$ & $1.6 \pm 0.1$ & $58.1 \pm 0.1$ & $40.3 \pm 0.2$ \\
\hline \multirow[t]{4}{*}{3} & 53 & 40 & 7 & 52.8 & 39.7 & 7.5 & as-cast & $(\gamma \mathrm{Co}, \mathrm{Fe})$ & $62.0 \pm 0.6$ & $37.7 \pm 0.6$ & $0.3 \pm 0.2$ \\
\hline & & & & & & & & $\mathrm{LaCo}_{13}$ & $43.3 \pm 0.9$ & $49.0 \pm 0.9$ & $7.7 \pm 0.2$ \\
\hline & & & & & & & & $\mathrm{La}_{2} \mathrm{Co}_{3}$ & 3.2 & 57.2 & 39.6 \\
\hline & & & & & & & & $\mathrm{La}_{2} \mathrm{Co}_{1.7}$ & 0.9 & 47.0 & 52.1 \\
\hline \multirow[t]{5}{*}{4} & 49 & 40 & 11 & 48.4 & 39.0 & 12.6 & as-cast & $(\gamma \mathrm{Co}, \mathrm{Fe})$ & $62.4 \pm 0.9$ & $37.1 \pm 0.9$ & $0.5 \pm 0.1$ \\
\hline & & & & & & & & $\mathrm{LaCo}_{13}$ & $43.3 \pm 0.4$ & $49.0 \pm 0.6$ & $7.7 \pm 0.2$ \\
\hline & & & & & & & & $\tau$ & $39.0 \pm 0.3$ & $49.5 \pm 0.3$ & $11.5 \pm 0.1$ \\
\hline & & & & & & & & $\mathrm{La}_{2} \mathrm{Co}_{3}$ & 3.2 & 56.1 & 40.7 \\
\hline & & & & & & & & $\mathrm{La}_{2} \mathrm{Co}_{1.7}$ & 1.0 & 46.8 & 52.2 \\
\hline \multirow[t]{4}{*}{5} & 5 & 60 & 35 & 4.9 & 58.8 & 36.3 & as-cast & $\mathrm{LaCo}_{5}$ & $10.3 \pm 0.2$ & $72.4 \pm 0.1$ & $17.3 \pm 0.3$ \\
\hline & & & & & & & & $\mathrm{La}_{2} \mathrm{Co}_{7}$ & $7.7 \pm 0.5$ & $69.3 \pm 0.7$ & $23.0 \pm 0.3$ \\
\hline & & & & & & & & $\mathrm{La}_{2} \mathrm{Co}_{3}$ & $1.8 \pm 0.2$ & $57.4 \pm 0.4$ & $40.8 \pm 0.2$ \\
\hline & & & & & & & & $\mathrm{La}_{2} \mathrm{Co}_{1.7}$ & $0.5 \pm 0.2$ & $46.2 \pm 0.4$ & $53.3 \pm 0.3$ \\
\hline \multirow[t]{4}{*}{6} & 23 & 70 & 7 & 23.1 & 69.5 & 7.4 & as-cast & $(\gamma \mathrm{Co}, \mathrm{Fe})$ & $28.7 \pm 0.1$ & $70.9 \pm 0.1$ & $0.4 \pm 0.1$ \\
\hline & & & & & & & & $\mathrm{LaCo}_{13}$ & $20.3 \pm 0.2$ & $72.2 \pm 0.1$ & $7.5 \pm 0.1$ \\
\hline & & & & & & & & $\mathrm{La}_{2} \mathrm{Co}_{7}$ & $9.2 \pm 0.2$ & $68.6 \pm 0.4$ & $22.2 \pm 0.3$ \\
\hline & & & & & & & & $\mathrm{La}_{2} \mathrm{Co}_{3}$ & 2.1 & 57.6 & 40.3 \\
\hline \multirow[t]{8}{*}{7} & 5 & 75 & 20 & 4.9 & 74.0 & 21.1 & as-cast & $\mathrm{LaCo}_{13}$ & $8.7 \pm 0.1$ & $83.4 \pm 0.1$ & $7.9 \pm 0.1$ \\
\hline & & & & & & & & $\mathrm{LaCo}_{5}$ & $4.1 \pm 0.1$ & $78.7 \pm 0.1$ & $17.2 \pm 0.2$ \\
\hline & & & & & & & & $\mathrm{La}_{5} \mathrm{Co}_{19}$ & $3.8 \pm 0.3$ & $74.6 \pm 0.2$ & $21.6 \pm 0.1$ \\
\hline & & & & & & & & $\mathrm{La}_{2} \mathrm{Co}_{7}$ & $3.8 \pm 0.1$ & $73.1 \pm 0.3$ & $23.1 \pm 0.4$ \\
\hline & & & & & & & & $\mathrm{La}_{2} \mathrm{Co}_{3}$ & $1.1 \pm 0.1$ & $58.6 \pm 0.1$ & $40.3 \pm 0.1$ \\
\hline & & & & 5.1 & 74.1 & 20.8 & $810^{\circ} \mathrm{C}, 4 \mathrm{~h}$ & $\mathrm{LaCo}_{5}$ & $6.0 \pm 0.2$ & $76.6 \pm 0.3$ & $17.4 \pm 0.1$ \\
\hline & & & & & & & & $\mathrm{La}_{5} \mathrm{Co}_{19}$ & $4.7 \pm 0.1$ & $73.8 \pm 0.1$ & $21.5 \pm 0.1$ \\
\hline & & & & & & & & $\mathrm{La}_{2} \mathrm{Co}_{7}$ & $4.4 \pm 0.2$ & $72.7 \pm 0.1$ & $22.9 \pm 0.1$ \\
\hline \multirow[t]{4}{*}{8} & 20 & 50 & 30 & 19.8 & 46.8 & 33.4 & as-cast & $(\gamma \mathrm{Co}, \mathrm{Fe})$ & $53.3 \pm 0.3$ & $45.6 \pm 0.2$ & $1.1 \pm 0.1$ \\
\hline & & & & & & & & $\tau$ & 35.0 & 53.7 & 11.3 \\
\hline & & & & & & & & $\mathrm{La}_{2} \mathrm{Co}_{3}$ & $2.3 \pm 0.1$ & $57.0 \pm 0.1$ & $40.7 \pm 0.1$ \\
\hline & & & & & & & & $\mathrm{La}_{2} \mathrm{Co}_{1.7}$ & $0.7 \pm 0.1$ & $46.4 \pm 0.2$ & $52.9 \pm 0.2$ \\
\hline \multirow[t]{5}{*}{9} & 38 & 55 & 7 & 38.2 & 54.6 & 7.2 & as-cast & $(\gamma \mathrm{Co}, \mathrm{Fe})$ & $46.1 \pm 0.1$ & $53.6 \pm 0.1$ & $0.3 \pm 0.1$ \\
\hline & & & & & & & & $\mathrm{LaCo}_{13}$ & $34.2 \pm 0.1$ & $58.2 \pm 0.1$ & $7.6 \pm 0.1$ \\
\hline & & & & & & & & $\mathrm{La}_{2} \mathrm{Co}_{3}$ & 3.0 & 56.9 & 40.1 \\
\hline & & & & 38.4 & 54.7 & 6.9 & $950^{\circ} \mathrm{C}, 94 \mathrm{~h}$ & $(\gamma \mathrm{Co}, \mathrm{Fe})$ & $49.4 \pm 0.2$ & $50.2 \pm 0.2$ & $0.4 \pm 0.1$ \\
\hline & & & & & & & & $\mathrm{LaCo}_{13}$ & $37.3 \pm 0.3$ & $55.2 \pm 0.3$ & $7.5 \pm 0.1$ \\
\hline
\end{tabular}


Table 4 continued

\begin{tabular}{|c|c|c|c|c|c|c|c|c|c|c|c|}
\hline \multirow[t]{3}{*}{ \# } & \multicolumn{6}{|c|}{ Phase composition, at. $\%$} & \multirow[t]{3}{*}{ Heat treatment } & \multicolumn{4}{|c|}{ EPMA data, at. $\%$} \\
\hline & \multicolumn{3}{|c|}{ Nominal } & \multicolumn{3}{|c|}{ Measured } & & \multirow[b]{2}{*}{ Phase } & \multirow[b]{2}{*}{$\mathrm{Fe}$} & \multirow[b]{2}{*}{$\mathrm{Co}$} & \multirow[b]{2}{*}{$\mathrm{La}$} \\
\hline & $\mathrm{Fe}$ & $\mathrm{Co}$ & $\mathrm{La}$ & $\mathrm{Fe}$ & $\mathrm{Co}$ & $\mathrm{La}$ & & & & & \\
\hline \multirow[t]{5}{*}{10} & 15 & 75 & 10 & 14.3 & 74.4 & 11.3 & as-cast & $(\gamma \mathrm{Co}, \mathrm{Fe})$ & $21.3 \pm 0.1$ & $78.0 \pm 0.2$ & $0.7 \pm 0.1$ \\
\hline & & & & & & & & $\mathrm{LaCo}_{13}$ & $15.2 \pm 0.1$ & $77.0 \pm 0.1$ & $7.8 \pm 0.1$ \\
\hline & & & & & & & & $\mathrm{LaCO}_{5}$ & $9.9 \pm 0.3$ & $72.6 \pm 0.5$ & $17.5 \pm 0.2$ \\
\hline & & & & & & & & $\mathrm{La}_{2} \mathrm{Co}_{7}$ & $7.8 \pm 0.1$ & $69.3 \pm 0.1$ & $22.9 \pm 0.1$ \\
\hline & & & & & & & & $\mathrm{La}_{2} \mathrm{Co}_{3}$ & 2.3 & 57.1 & 40.6 \\
\hline \multirow[t]{4}{*}{11} & 33 & 50 & 17 & 33.3 & 49.3 & 17.4 & as-cast & $(\gamma \mathrm{Co}, \mathrm{Fe})$ & $53.2 \pm 0.2$ & $46.4 \pm 0.3$ & $0.4 \pm 0.1$ \\
\hline & & & & & & & & $\mathrm{LaCo}_{13}$ & $35.9 \pm 0.2$ & $56.2 \pm 0.2$ & $7.9 \pm 0.1$ \\
\hline & & & & & & & & $\mathrm{La}_{2} \mathrm{Co}_{3}$ & $2.5 \pm 0.3$ & $56.9 \pm 0.2$ & $40.6 \pm 0.1$ \\
\hline & & & & & & & & $\mathrm{La}_{2} \mathrm{Co}_{1.7}$ & $0.9 \pm 0.1$ & $46.2 \pm 0.5$ & $52.9 \pm 0.6$ \\
\hline \multirow[t]{4}{*}{12} & 48 & 45 & 7 & 48.1 & 44.6 & 7.3 & as-cast & $(\gamma \mathrm{Co} . \mathrm{Fe})$ & $56.5 \pm 0.3$ & $43.0 \pm 0.3$ & $0.5 \pm 0.1$ \\
\hline & & & & & & & & $\tau$ & $39.4 \pm 0.7$ & $48.9 \pm 0.6$ & $11.7 \pm 0.4$ \\
\hline & & & & & & & & $\mathrm{La}_{2} \mathrm{Co}_{3}$ & 3.0 & 56.0 & 41.0 \\
\hline & & & & & & & & $\mathrm{La}_{2} \mathrm{Co}_{1.7}$ & 1.0 & 46.9 & 52.1 \\
\hline \multirow[t]{4}{*}{13} & 44 & 45 & 11 & 44.1 & 44.2 & 11.7 & as-cast & $(\gamma \mathrm{Co}, \mathrm{Fe})$ & $57.2 \pm 0.4$ & $42.1 \pm 0.4$ & $0.7 \pm 0.1$ \\
\hline & & & & & & & & $\tau$ & 40.5 & 48.2 & 11.3 \\
\hline & & & & & & & & $\mathrm{La}_{2} \mathrm{Co}_{3}$ & 3.0 & 56.4 & 40.6 \\
\hline & & & & & & & & $\mathrm{La}_{2} \mathrm{Co}_{1.7}$ & 1.0 & 46.6 & 52.4 \\
\hline \multirow[t]{3}{*}{14} & 15 & 83 & 2 & 15.5 & 82.5 & 2.0 & as-cast & $(\gamma \mathrm{Co}, \mathrm{Fe})$ & $16.3 \pm 0.1$ & $83.6 \pm 0.1$ & $0.1 \pm 0.1$ \\
\hline & & & & & & & & $\mathrm{LaCo}_{13}$ & $12.0 \pm 0.2$ & $80.7 \pm 0.2$ & $7.3 \pm 0.1$ \\
\hline & & & & & & & & $\mathrm{La}_{2} \mathrm{Co}_{7}$ & $6.4 \pm 0.4$ & $70.7 \pm 0.2$ & $22.9 \pm 0.6$ \\
\hline \multirow[t]{2}{*}{15} & 40 & 25 & 35 & 38.3 & 25.2 & 36.5 & as-cast & $(\gamma \mathrm{Co}, \mathrm{Fe})$ & 82.1 & 17.0 & 0.9 \\
\hline & & & & & & & & eutectic $\left(\mathrm{La}_{2} \mathrm{Co}_{1.7}+\mathrm{La}_{3} \mathrm{Co}\right)$ & 0.9 & 29.0 & 70.1 \\
\hline \multirow[t]{2}{*}{16} & 60 & 25 & 15 & 59.0 & 25.0 & 16.0 & as-cast & $(\gamma \mathrm{Co}, \mathrm{Fe})$ & $78.8 \pm 0.2$ & $20.6 \pm 0.1$ & $0.6 \pm 0.1$ \\
\hline & & & & & & & & eutectic $\left(\mathrm{La}_{2} \mathrm{Co}_{1.7}+\mathrm{La}_{3} \mathrm{Co}\right)$ & $0.9 \pm 0.1$ & $29.7 \pm 0.1$ & $69.4 \pm 0.1$ \\
\hline \multirow[t]{3}{*}{17} & 60 & 15 & 25 & 57.5 & 15.6 & 26.9 & as-cast & $(\gamma \mathrm{Co}, \mathrm{Fe})$ & $88.8 \pm 0.2$ & $10.4 \pm 0.2$ & $0.8 \pm 0.1$ \\
\hline & & & & & & & & $(\beta \mathrm{La})$ & $0.0 \pm 0.0$ & $0.0 \pm 0.0$ & $100.0 \pm 0.0$ \\
\hline & & & & & & & & $\mathrm{La}_{3} \mathrm{Co}$ & 0.0 & 24.2 & 75.8 \\
\hline \multirow[t]{2}{*}{18} & 40 & 35 & 25 & 39.0 & 34.3 & 26.7 & as-cast & $(\gamma \mathrm{Co}, \mathrm{Fe})$ & 69.4 & $29.7 \pm 0.5$ & $0.9 \pm 0.1$ \\
\hline & & & & & & & & $\mathrm{La}_{2} \mathrm{Co}_{1.7}$ & $1.0 \pm 0.1$ & $46.0 \pm 0.3$ & $53.0 \pm 0.2$ \\
\hline 19 & 35 & 15 & 50 & 31.1 & 16.3 & 52.6 & as-cast & - & - & - & - \\
\hline 20 & 25 & 25 & 50 & 19.6 & 26.4 & 54.0 & as-cast & - & - & - & - \\
\hline \multirow[t]{3}{*}{21} & 63 & 30 & 7 & 62.4 & 30.3 & 7.3 & as-cast & $(\gamma \mathrm{Co}, \mathrm{Fe})$ & $72.0 \pm 0.3$ & $27.6 \pm 0.3$ & $0.4 \pm 0.1$ \\
\hline & & & & & & & & $\mathrm{La}_{2} \mathrm{Co}_{3}$ & 1.3 & 57.8 & 40.9 \\
\hline & & & & & & & & $\mathrm{La}_{2} \mathrm{Co}_{1.7}$ & 1.0 & 46.4 & 52.6 \\
\hline 22 & 10 & 79 & 11 & 10.2 & 78.2 & 11.6 & as-cast & $(\gamma \mathrm{Co}, \mathrm{Fe})$ & $15.5 \pm 0.2$ & $83.9 \pm 0.2$ & $0.6 \pm 0.1$ \\
\hline & & & & & & & & $\mathrm{LaCo}_{13}$ & $11.1 \pm 0.2$ & $81.3 \pm 0.1$ & $7.6 \pm 0.1$ \\
\hline & & & & & & & & $\mathrm{LaCo}_{5}$ & $7.2 \pm 0.5$ & $75.9 \pm 0.3$ & $16.9 \pm 0.3$ \\
\hline & & & & & & & & $\mathrm{La}_{2} \mathrm{Co}_{7}$ & $6.2 \pm 0.2$ & $71.1 \pm 0.5$ & $22.7 \pm 0.2$ \\
\hline & & & & - & - & - & $970{ }^{\circ} \mathrm{C}, 3 \mathrm{~h}$ & $\mathrm{LaCo}_{13}$ & $12.6 \pm 0.3$ & $79.7 \pm 0.3$ & $7.7 \pm 0.1$ \\
\hline & & & & & & & & $\mathrm{LaCo}_{5}$ & $5.7 \pm 0.3$ & $77.1 \pm 0.3$ & $17.2 \pm 0.2$ \\
\hline 23 & 29 & 60 & 11 & 28.5 & 59.3 & 12.2 & as-cast & $(\gamma \mathrm{Co}, \mathrm{Fe})$ & $40.3 \pm 0.4$ & $59.0 \pm 0.4$ & $0.7 \pm 0.2$ \\
\hline & & & & & & & & $\mathrm{LaCo}_{13}$ & $28.2 \pm 0.3$ & $64.2 \pm 0.4$ & $7.6 \pm 0.1$ \\
\hline & & & & & & & & $\mathrm{La}_{2} \mathrm{Co}_{3}$ & $2.8 \pm 0.1$ & $56.9 \pm 0.2$ & $40.3 \pm 0.3$ \\
\hline
\end{tabular}


Table 4 continued

\begin{tabular}{|c|c|c|c|c|c|c|c|c|c|c|c|}
\hline \multirow[t]{3}{*}{$\#$} & \multicolumn{6}{|c|}{ Phase composition, at.\% } & \multirow[t]{3}{*}{ Heat treatment } & \multirow{2}{*}{\multicolumn{4}{|c|}{ EPMA data, at. $\%$}} \\
\hline & \multicolumn{3}{|c|}{ Nominal } & \multicolumn{3}{|c|}{ Measured } & & & & & \\
\hline & $\mathrm{Fe}$ & $\mathrm{Co}$ & $\mathrm{La}$ & $\mathrm{Fe}$ & $\mathrm{Co}$ & $\mathrm{La}$ & & Phase & $\mathrm{Fe}$ & Co & $\mathrm{La}$ \\
\hline \multirow[t]{5}{*}{28} & 5 & 88 & 7 & 5.1 & 87.5 & 7.4 & as-cast & $(\gamma \mathrm{Co}, \mathrm{Fe})$ & $7.0 \pm 0.1$ & $92.6 \pm 0.2$ & $0.4 \pm 0.1$ \\
\hline & & & & & & & & $\mathrm{LaCo}_{13}$ & $4.8 \pm 0.1$ & $87.7 \pm 0.1$ & $7.5 \pm 0.1$ \\
\hline & & & & & & & & $\mathrm{LaCo}_{5}$ & $3.1 \pm 0.1$ & $80.1 \pm 0.1$ & $16.8 \pm 0.2$ \\
\hline & & & & & & & & $\mathrm{La}_{5} \mathrm{Co}_{19}$ & $2.7 \pm 0.1$ & $76.0 \pm 0.2$ & $21.3 \pm 0.2$ \\
\hline & & & & & & & & $\mathrm{La}_{2} \mathrm{Co}_{7}$ & $2.5 \pm 0.1$ & $74.5 \pm 0.1$ & $23.0 \pm 0.2$ \\
\hline 29 & 68 & 25 & 7 & 68.2 & 25 & 6.8 & as-cast & $(\gamma \mathrm{Co}, \mathrm{Fe})$ & $76.7 \pm 0.8$ & $23.3 \pm 0.8$ & $0.0 \pm 0.0$ \\
\hline \multirow[t]{7}{*}{31} & 18 & 45 & 37 & 17.4 & 44.4 & 38.2 & as-cast & $(\gamma \mathrm{Co}, \mathrm{Fe})$ & $55.7 \pm 0.9$ & $43.4 \pm 0.9$ & $0.9 \pm 0.1$ \\
\hline & & & & & & & & $\tau$ & $31.4 \pm 0.4$ & $57.1 \pm 0.5$ & $11.5 \pm 0.3$ \\
\hline & & & & & & & & $\mathrm{La}_{2} \mathrm{Co}_{3}$ & $2.5 \pm 0.2$ & $57.0 \pm 0.4$ & $40.5 \pm 0.3$ \\
\hline & & & & & & & & $\mathrm{La}_{2} \mathrm{Co}_{1.7}$ & $0.6 \pm 0.7$ & $46.4 \pm 0.1$ & $53.0 \pm 0.7$ \\
\hline & & & & & & & & $\mathrm{La}_{3} \mathrm{Co}$ & 0.0 & 24.8 & 75.2 \\
\hline & & & & & & & & eutectic $\left(\mathrm{La}_{2} \mathrm{Co}_{1.7}+\mathrm{La}_{3} \mathrm{Co}\right)$ & 1.2 & 31.6 & 67.2 \\
\hline & & & & & & & & & 0.1 & 32.2 & 67.7 \\
\hline \multirow[t]{5}{*}{32} & 12 & 77 & 11 & 12.0 & 76.8 & 11.2 & as-cast & $(\gamma \mathrm{Co} . \mathrm{Fe})$ & $18.3 \pm 0.1$ & $81.1 \pm 0.1$ & $0.6 \pm 0.1$ \\
\hline & & & & & & & & $\mathrm{LaCo}_{13}$ & $13.0 \pm 0.2$ & $79.3 \pm 0.1$ & $7.7 \pm 0.1$ \\
\hline & & & & & & & & $\mathrm{LaCo}_{5}$ & $8.9 \pm 0.7$ & $74.2 \pm 0.7$ & $16.9 \pm 0.1$ \\
\hline & & & & & & & & $\mathrm{La}_{2} \mathrm{Co}_{7}$ & $6.8 \pm 0.4$ & $70.7 \pm 0.6$ & $22.5 \pm 0.4$ \\
\hline & & & & & & & & $\mathrm{La}_{2} \mathrm{Co}_{3}$ & 3.6 & 56.1 & 40.3 \\
\hline \multirow[t]{5}{*}{34} & 10 & 30 & 60 & 9.3 & 29.9 & 60.8 & as-cast & $(\alpha \mathrm{Co}, \mathrm{Fe})$ & $76.4 \pm 0.1$ & $23.0 \pm 0.1$ & $0.6 \pm 0.1$ \\
\hline & & & & & & & & eutectic $\left(\mathrm{La}_{2} \mathrm{Co}_{1.7}+\mathrm{La}_{3} \mathrm{Co}\right)$ & $0.4 \pm 0.2$ & $31.1 \pm 0.6$ & $68.5 \pm 0.6$ \\
\hline & & & & 9.0 & 29.3 & 61.7 & $510^{\circ} \mathrm{C}, 1 \mathrm{~h}$ & $(\alpha \mathrm{Co}, \mathrm{Fe})$ & $74.7 \pm 0.1$ & $24.7 \pm 0.1$ & $0.6 \pm 0.1$ \\
\hline & & & & & & & & $\mathrm{La}_{2} \mathrm{Co}_{1.7}$ & $0.0 \pm 0.0$ & $46.5 \pm 0.2$ & $53.5 \pm 0.2$ \\
\hline & & & & & & & & $\mathrm{La}_{3} \mathrm{Co}$ & $0.0 \pm 0.0$ & $24.8 \pm 0.1$ & $75.2 \pm 0.1$ \\
\hline \multirow[t]{2}{*}{35} & 10 & 25 & 65 & 8.2 & 25.2 & 66.6 & as-cast & $(\alpha \mathrm{Co}, \mathrm{Fe})$ & $82.6 \pm 0.3$ & $16.5 \pm 0.3$ & $0.9 \pm 0.1$ \\
\hline & & & & & & & & $\mathrm{La}_{3} \mathrm{Co}$ & $0.0 \pm 0.1$ & $24.9 \pm 0.2$ & $75.1 \pm 0.2$ \\
\hline \multirow[t]{6}{*}{36} & 10 & 10 & 80 & 9.2 & 10.1 & 80.7 & as-cast & $(\beta \mathrm{La})$ & $0.0 \pm 0.0$ & $0.0 \pm 0.0$ & $100.0 \pm 0.0$ \\
\hline & & & & & & & & $\mathrm{La}_{3} \mathrm{Co}$ & $0.2 \pm 0.3$ & $23.2 \pm 0.2$ & $76.6 \pm 0.3$ \\
\hline & & & & & & & & $(\alpha \mathrm{Co}, \mathrm{Fe})$ & 96.3 & 3.0 & 0.7 \\
\hline & & & & 9.3 & 10.1 & 80.6 & $520^{\circ} \mathrm{C}, 2 \mathrm{~h}$ & $(\alpha \mathrm{Fe}, \mathrm{Co})$ & $95.9 \pm 0.4$ & $3.2 \pm 0.2$ & $0.9 \pm 0.1$ \\
\hline & & & & & & & & $(\beta \mathrm{La})$ & $0.0 \pm 0.0$ & $0.0 \pm 0.0$ & $100.0 \pm 0.0$ \\
\hline & & & & & & & & $\mathrm{La}_{3} \mathrm{Co}$ & $0.0 \pm 0.1$ & $24.2 \pm 0.2$ & $75.8 \pm 0.2$ \\
\hline \multirow[t]{3}{*}{38} & 2 & 33 & 65 & 1.5 & 32.5 & 66.0 & as-cast & $\mathrm{La}_{2} \mathrm{Co}_{1.7}$ & $0.8 \pm 0.1$ & $45.7 \pm 0.4$ & $53.5 \pm 0.4$ \\
\hline & & & & & & & & $\mathrm{La}_{3} \mathrm{Co}$ & $0.1 \pm 0.1$ & $25.0 \pm 0.6$ & $74.9 \pm 0.5$ \\
\hline & & & & & & & & eutectic $\left(\mathrm{La}_{2} \mathrm{Co}_{1.7}+\mathrm{La}_{3} \mathrm{Co}\right)$ & $0.9 \pm 0.1$ & $30.9 \pm 0.1$ & $68.2 \pm 0.3$ \\
\hline \multirow[t]{2}{*}{39} & 2 & 23 & 75 & 1.9 & 23.0 & 75.1 & as-cast & $(\alpha \mathrm{Co}, \mathrm{Fe})$ & 81.2 & 18.4 & 0.4 \\
\hline & & & & & & & & $\mathrm{La}_{3} \mathrm{Co}$ & $0.2 \pm 0.2$ & $24.0 \pm 0.1$ & $75.8 \pm 0.3$ \\
\hline \multirow[t]{3}{*}{37} & 2 & 38 & 60 & 1.8 & 37.3 & 60.9 & as-cast & $(\alpha \mathrm{Co}, \mathrm{Fe})$ & $59.0 \pm 0.3$ & $40.4 \pm 0.4$ & $0.6 \pm 0.1$ \\
\hline & & & & & & & & $\mathrm{La}_{2} \mathrm{Co}_{1.7}$ & $0.7 \pm 0.1$ & $45.5 \pm 0.2$ & $53.8 \pm 0.2$ \\
\hline & & & & & & & & $\mathrm{La}_{3} \mathrm{Co}$ & $0.0 \pm 0.1$ & $25.2 \pm 0.3$ & $74.8 \pm 0.3$ \\
\hline \multirow[t]{3}{*}{42} & 15 & 35 & 50 & 15.8 & 35.9 & 48.3 & as-cast & $(\gamma \mathrm{Co}, \mathrm{Fe})$ & $67.2 \pm 0.6$ & $31.9 \pm 0.5$ & $0.9 \pm 0.1$ \\
\hline & & & & & & & & $\mathrm{La}_{2} \mathrm{Co}_{1.7}$ & $0.0 \pm 0.0$ & $46.3 \pm 0.3$ & $53.7 \pm 0.3$ \\
\hline & & & & & & & & $\mathrm{La}_{3} \mathrm{Co}$ & $0.0 \pm 0.0$ & $25.2 \pm 0.5$ & $74.8 \pm 0.5$ \\
\hline
\end{tabular}


Table 4 continued

\begin{tabular}{|c|c|c|c|c|c|c|c|c|c|c|c|}
\hline \multirow[t]{3}{*}{$\#$} & \multicolumn{6}{|c|}{ Phase composition, at. $\%$} & \multirow[t]{3}{*}{ Heat treatment } & \multicolumn{4}{|c|}{ EPMA data, at.\% } \\
\hline & \multicolumn{3}{|c|}{ Nominal } & \multicolumn{3}{|c|}{ Measured } & & \multirow[b]{2}{*}{ Phase } & \multirow[b]{2}{*}{$\mathrm{Fe}$} & \multirow[b]{2}{*}{$\mathrm{Co}$} & \multirow[b]{2}{*}{$\mathrm{La}$} \\
\hline & $\mathrm{Fe}$ & $\mathrm{Co}$ & $\mathrm{La}$ & $\mathrm{Fe}$ & $\mathrm{Co}$ & $\mathrm{La}$ & & & & & \\
\hline \multirow[t]{4}{*}{44} & 10 & 75 & 15 & 10.0 & 74.3 & 15.7 & as-cast & $\mathrm{LaCo}_{13}$ & $13.2 \pm 0.3$ & $79.1 \pm 0.3$ & $7.7 \pm 0.1$ \\
\hline & & & & & & & & $\mathrm{LaCo}_{5}$ & $8.2 \pm 0.4$ & $75.0 \pm 0.4$ & $16.8 \pm 0.2$ \\
\hline & & & & & & & & $\mathrm{La}_{2} \mathrm{Co}_{7}$ & $6.2 \pm 0.3$ & $71.3 \pm 0.2$ & $22.5 \pm 0.2$ \\
\hline & & & & & & & & $\mathrm{La}_{2} \mathrm{Co}_{3}$ & $2.2 \pm 0.1$ & $57.7 \pm 0.1$ & $40.1 \pm 0.1$ \\
\hline \multirow[t]{10}{*}{45} & 10 & 65 & 25 & 9.4 & 64.2 & 26.4 & as-cast & $\mathrm{LaCo}_{13}$ & 17.9 & 74.3 & 7.8 \\
\hline & & & & & & & & $\tau$ & $16.7 \pm 0.2$ & $72.1 \pm 0.3$ & $11.2 \pm 0.1$ \\
\hline & & & & & & & & $\mathrm{LaCO}_{5}$ & $8.6 \pm 0.6$ & $74.1 \pm 0.6$ & $17.3 \pm 0.1$ \\
\hline & & & & & & & & $\mathrm{La}_{2} \mathrm{Co}_{7}$ & $7.4 \pm 0.1$ & $69.8 \pm 0.2$ & $22.8 \pm 0.2$ \\
\hline & & & & & & & & $\mathrm{La}_{2} \mathrm{Co}_{3}$ & $2.0 \pm 0.2$ & $57.4 \pm 0.3$ & $40.6 \pm 0.2$ \\
\hline & & & & & & & & $\mathrm{La}_{2} \mathrm{Co}_{1.7}$ & $0.7 \pm 0.2$ & $46.5 \pm 0.2$ & $52.8 \pm 0.1$ \\
\hline & & & & & & & & eutectic $\left(\mathrm{La}_{2} \mathrm{Co}_{1.7}+\mathrm{La}_{3} \mathrm{Co}\right)$ & $1.0 \pm 0.1$ & $32.1 \pm 0.1$ & $66.9 \pm 0.2$ \\
\hline & & & & 9.3 & 64.2 & 26.5 & $660^{\circ} \mathrm{C}, 2 \mathrm{~h}$ & $\tau$ & $20.1 \pm 0.7$ & $68.2 \pm 0.9$ & $11.7 \pm 0.2$ \\
\hline & & & & & & & & $\mathrm{La}_{2} \mathrm{Co}_{3}$ & $1.1 \pm 0.1$ & $58.2 \pm 0.1$ & $40.7 \pm 0.1$ \\
\hline & & & & & & & & $\mathrm{La}_{2} \mathrm{Co}_{7}$ & $8.3 \pm 0.4$ & $68.8 \pm 0.4$ & $22.9 \pm 0.4$ \\
\hline \multirow[t]{2}{*}{46} & 20 & 55 & 25 & 20.3 & 54.2 & 25.5 & as-cast & $\mathrm{LaCo}_{13}$ & $33.6 \pm 0.3$ & $58.5 \pm 0.3$ & $7.9 \pm 0.1$ \\
\hline & & & & & & & & $\mathrm{La}_{2} \mathrm{Co}_{3}$ & $1.9 \pm 0.1$ & $57.5 \pm 0.3$ & $40.6 \pm 0.2$ \\
\hline \multirow[t]{4}{*}{47} & 10 & 70 & 20 & 9.9 & 68.7 & 21.4 & as-cast & $\mathrm{LaCo}_{13}$ & $16.2 \pm 0.3$ & $75.9 \pm 0.4$ & $7.9 \pm 0.1$ \\
\hline & & & & & & & & $\mathrm{LaCO}_{5}$ & $9.0 \pm 0.2$ & $74.0 \pm 0.2$ & $17.0 \pm 0.1$ \\
\hline & & & & & & & & $\mathrm{La}_{2} \mathrm{Co}_{7}$ & $7.5 \pm 0.3$ & $69.4 \pm 0.3$ & $23.1 \pm 0.2$ \\
\hline & & & & & & & & $\mathrm{La}_{2} \mathrm{Co}_{3}$ & $2.1 \pm 0.1$ & $57.5 \pm 0.3$ & $40.4 \pm 0.3$ \\
\hline \multirow[t]{5}{*}{48} & 15 & 65 & 20 & 14.9 & 63.9 & 21.2 & as-cast & $\mathrm{LaCo}_{13}$ & $22.7 \pm 0.3$ & $69.4 \pm 0.3$ & $7.9 \pm 0.1$ \\
\hline & & & & & & & & $\mathrm{LaCo}_{5}$ & $9.2 \pm 0.2$ & $73.3 \pm 0.5$ & $17.5 \pm 0.3$ \\
\hline & & & & & & & & $\mathrm{La}_{2} \mathrm{Co}_{7}$ & $7.8 \pm 0.4$ & $69.3 \pm 0.5$ & $22.9 \pm 0.2$ \\
\hline & & & & & & & & $\mathrm{La}_{2} \mathrm{Co}_{3}$ & $2.5 \pm 0.3$ & $57.2 \pm 0.3$ & $40.3 \pm 0.3$ \\
\hline & & & & & & & & $\mathrm{La}_{2} \mathrm{Co}_{1.7}$ & $0.7 \pm 0.2$ & $47.3 \pm 0.1$ & $52.2 \pm 0.1$ \\
\hline \multirow[t]{5}{*}{49} & 10 & 67.5 & 22.5 & 9.8 & 66.3 & 23.9 & as-cast & $\mathrm{LaCo}_{13}$ & $17.4 \pm 0.3$ & $74.7 \pm 0.3$ & $7.9 \pm 0.1$ \\
\hline & & & & & & & & $\mathrm{LaCo}_{5}$ & $8.4 \pm 0.9$ & $74.3 \pm 0.9$ & $17.3 \pm 0.3$ \\
\hline & & & & & & & & $\mathrm{La}_{2} \mathrm{Co}_{7}$ & $7.5 \pm 0.2$ & $69.3 \pm 0.3$ & $23.2 \pm 0.1$ \\
\hline & & & & & & & & $\mathrm{La}_{2} \mathrm{Co}_{3}$ & $2.4 \pm 0.1$ & $57.1 \pm 0.1$ & $40.5 \pm 0.1$ \\
\hline & & & & & & & & $\mathrm{La}_{2} \mathrm{Co}_{1.7}$ & $0.0 \pm 0.0$ & $47.1 \pm 0.3$ & $52.9 \pm 0.3$ \\
\hline \multirow[t]{5}{*}{50} & 15 & 60 & 25 & 14.6 & 58.7 & 26.7 & as-cast & $\mathrm{LaCo}_{13}$ & $27.5 \pm 0.2$ & $64.6 \pm 0.3$ & $7.9 \pm 0.1$ \\
\hline & & & & & & & & $\tau$ & $24.7 \pm 0.3$ & $63.9 \pm 0.3$ & $11.4 \pm 0.1$ \\
\hline & & & & & & & & $\mathrm{La}_{2} \mathrm{Co}_{7}$ & $6.8 \pm 0.4$ & $70.3 \pm 0.5$ & $22.9 \pm 0.1$ \\
\hline & & & & & & & & $\mathrm{La}_{2} \mathrm{Co}_{3}$ & $2.0 \pm 0.2$ & $57.2 \pm 0.2$ & $40.8 \pm 0.3$ \\
\hline & & & & & & & & $\mathrm{La}_{2} \mathrm{Co}_{1.7}$ & $0.0 \pm 0.0$ & $46.5 \pm 0.2$ & $53.5 \pm 0.0$ \\
\hline \multirow[t]{8}{*}{54} & 10 & 62 & 28 & 8.9 & 62.3 & 28.8 & as-cast & $\tau$ & $18.0 \pm 0.2$ & $70.7 \pm 0.1$ & $11.3 \pm 0.1$ \\
\hline & & & & & & & & $\mathrm{LaCO}_{5}$ & $8.2 \pm 0.5$ & $74.3 \pm 0.2$ & $17.5 \pm 0.2$ \\
\hline & & & & & & & & $\mathrm{La}_{2} \mathrm{Co}_{7}$ & $7.4 \pm 0.3$ & $69.5 \pm 0.7$ & $23.1 \pm 0.4$ \\
\hline & & & & & & & & $\mathrm{La}_{2} \mathrm{Co}_{3}$ & $1.6 \pm 0.2$ & $57.7 \pm 0.3$ & $40.7 \pm 0.3$ \\
\hline & & & & & & & & $\mathrm{La}_{2} \mathrm{Co}_{1.7}$ & $0.9 \pm 0.2$ & $46.3 \pm 0.9$ & $52.8 \pm 0.8$ \\
\hline & & & & 8.5 & 63.1 & 28.4 & $660^{\circ} \mathrm{C}, 2 \mathrm{~h}$ & $\tau$ & $17.5 \pm 0.2$ & $70.9 \pm 0.2$ & $11.6 \pm 0.1$ \\
\hline & & & & & & & & $\mathrm{La}_{2} \mathrm{Co}_{3}$ & $1.2 \pm 0.2$ & $58.5 \pm 0.2$ & $40.3 \pm 0.1$ \\
\hline & & & & & & & & $\mathrm{La}_{2} \mathrm{Co}_{7}$ & $7.9 \pm 0.2$ & $69.5 \pm 0.3$ & $22.6 \pm 0.2$ \\
\hline
\end{tabular}


Table 4 continued

\begin{tabular}{|c|c|c|c|c|c|c|c|c|c|c|c|}
\hline \multirow[t]{3}{*}{ \# } & \multicolumn{6}{|c|}{ Phase composition, at. $\%$} & \multirow[t]{3}{*}{ Heat treatment } & \multicolumn{4}{|c|}{ EPMA data, at. $\%$} \\
\hline & \multicolumn{3}{|c|}{ Nominal } & \multicolumn{3}{|c|}{ Measured } & & \multirow[b]{2}{*}{ Phase } & \multirow[b]{2}{*}{$\mathrm{Fe}$} & \multirow[b]{2}{*}{ Co } & \multirow[b]{2}{*}{$\mathrm{La}$} \\
\hline & $\mathrm{Fe}$ & Co & $\mathrm{La}$ & $\mathrm{Fe}$ & Co & $\mathrm{La}$ & & & & & \\
\hline \multirow[t]{4}{*}{55} & 15 & 55 & 30 & 14.3 & 53.8 & 31.9 & as-cast & $\tau$ & $29.6 \pm 0.4$ & $58.9 \pm 0.2$ & $11.5 \pm 0.2$ \\
\hline & & & & & & & & $\mathrm{La}_{2} \mathrm{Co}_{3}$ & $1.7 \pm 0.2$ & $57.5 \pm 0.1$ & $40.8 \pm 0.1$ \\
\hline & & & & & & & & $\mathrm{La}_{2} \mathrm{Co}_{1.7}$ & $0.3 \pm 0.4$ & $46.0 \pm 0.3$ & $53.7 \pm 0.4$ \\
\hline & & & & & & & & eutectic $\left(\mathrm{La}_{2} \mathrm{Co}_{1.7}+\mathrm{La}_{3} \mathrm{Co}\right)$ & 0.1 & 30.2 & 69.7 \\
\hline \multirow[t]{5}{*}{57} & 10 & 60 & 30 & 9.6 & 58.6 & 31.8 & as-cast & $\tau$ & $20.5 \pm 0.2$ & $68.1 \pm 0.2$ & $11.4 \pm 0.1$ \\
\hline & & & & & & & & $\mathrm{La}_{2} \mathrm{Co}_{7}$ & $7.9 \pm 0.5$ & $69.3 \pm 0.5$ & $22.8 \pm 0.1$ \\
\hline & & & & & & & & $\mathrm{La}_{2} \mathrm{Co}_{3}$ & $2.2 \pm 0.1$ & $57.1 \pm 0.2$ & $40.7 \pm 0.1$ \\
\hline & & & & & & & & $\mathrm{La}_{2} \mathrm{Co}_{1.7}$ & $0.5 \pm 0.4$ & $46.0 \pm 0.5$ & $53.5 \pm 0.4$ \\
\hline & & & & & & & & eutectic $\left(\mathrm{La}_{2} \mathrm{Co}_{1.7}+\mathrm{La}_{3} \mathrm{Co}\right)$ & 0.3 & 29.8 & 69.9 \\
\hline \multirow[t]{4}{*}{58} & 10 & 55 & 35 & 9.8 & 53.5 & 36.6 & as-cast & $\tau$ & $25.8 \pm 0.5$ & $62.8 \pm 0.3$ & $11.4 \pm 0.1$ \\
\hline & & & & & & & & $\mathrm{La}_{2} \mathrm{Co}_{3}$ & $1.1 \pm 0.1$ & $58.5 \pm 0.1$ & $40.4 \pm 0.1$ \\
\hline & & & & & & & & $\mathrm{La}_{2} \mathrm{Co}_{1.7}$ & $0.9 \pm 0.3$ & $46.0 \pm 0.1$ & $53.1 \pm 0.2$ \\
\hline & & & & & & & & eutectic $\left(\mathrm{La}_{2} \mathrm{Co}_{1.7}+\mathrm{La}_{3} \mathrm{Co}\right)$ & $0.6 \pm 0.3$ & $30.0 \pm 0.9$ & $69.4 \pm 0.6$ \\
\hline \multirow[t]{7}{*}{59} & 10 & 50 & 40 & 8.9 & 49.8 & 41.3 & as-cast & $\tau$ & $28.9 \pm 0.2$ & $59.5 \pm 0.2$ & $11.6 \pm 0.1$ \\
\hline & & & & & & & & $\mathrm{La}_{2} \mathrm{Co}_{3}$ & $1.7 \pm 0.2$ & $57.6 \pm 0.2$ & $40.7 \pm 0.1$ \\
\hline & & & & & & & & $\mathrm{La}_{2} \mathrm{Co}_{1.7}$ & $0.8 \pm 0.2$ & $45.8 \pm 0.6$ & $53.4 \pm 0.5$ \\
\hline & & & & & & & & eutectic $\left(\mathrm{La}_{2} \mathrm{Co}_{1.7}+\mathrm{La}_{3} \mathrm{Co}\right)$ & 0.6 & 33.3 & 66.1 \\
\hline & & & & 8.7 & 49.7 & 41.6 & $560^{\circ} \mathrm{C}, 2 \mathrm{~h}$ & $(\alpha \mathrm{Co}, \mathrm{Fe})$ & $62.5 \pm 0.3$ & $37.1 \pm 0.5$ & $0.4 \pm 0.1$ \\
\hline & & & & & & & & $\mathrm{La}_{2} \mathrm{Co}_{3}$ & $2.2 \pm 0.1$ & $57.1 \pm 0.3$ & $40.7 \pm 0.1$ \\
\hline & & & & & & & & $\mathrm{La}_{2} \mathrm{Co}_{1.7}$ & $0.0 \pm 0.2$ & $47.0 \pm 0.2$ & $53.0 \pm 0.2$ \\
\hline \multirow[t]{4}{*}{60} & 10 & 45 & 45 & 9.8 & 43.6 & 46.6 & as-cast & $\tau$ & $38.0 \pm 0.1$ & $50.2 \pm 0.1$ & $11.8 \pm 0.1$ \\
\hline & & & & & & & & $\mathrm{La}_{2} \mathrm{Co}_{3}$ & $2.2 \pm 0.1$ & $56.9 \pm 0.1$ & $40.9 \pm 0.2$ \\
\hline & & & & & & & & $\mathrm{La}_{2} \mathrm{Co}_{1.7}$ & $0.7 \pm 0.2$ & $45.6 \pm 0.4$ & $53.7 \pm 0.3$ \\
\hline & & & & & & & & eutectic $\left(\mathrm{La}_{2} \mathrm{Co}_{1.7}+\mathrm{La}_{3} \mathrm{Co}\right)$ & $0.5 \pm 0.1$ & $31.5 \pm 0.9$ & $68.0 \pm 0.9$ \\
\hline \multirow[t]{4}{*}{61} & 15 & 45 & 40 & 14.3 & 44.3 & 41.4 & as-cast & $\tau$ & $40.3 \pm 0.3$ & $48.0 \pm 0.1$ & $11.7 \pm 0.2$ \\
\hline & & & & & & & & $\mathrm{La}_{2} \mathrm{Co}_{3}$ & $2.3 \pm 0.1$ & $57.1 \pm 0.1$ & $40.6 \pm 0.1$ \\
\hline & & & & & & & & $\mathrm{La}_{2} \mathrm{Co}_{1.7}$ & $0.4 \pm 0.5$ & $45.7 \pm 0.3$ & $53.9 \pm 0.3$ \\
\hline & & & & & & & & eutectic $\left(\mathrm{La}_{2} \mathrm{Co}_{1.7}+\mathrm{La}_{3} \mathrm{Co}\right)$ & 0.1 & 31.3 & 68.6 \\
\hline \multirow[t]{8}{*}{62} & 5 & 50 & 45 & 4.3 & 47.8 & 47.9 & as-cast & $\tau$ & $25.7 \pm 0.3$ & $62.8 \pm 0.3$ & $11.5 \pm 0.1$ \\
\hline & & & & & & & & $\mathrm{La}_{2} \mathrm{Co}_{3}$ & $1.6 \pm 0.1$ & $57.8 \pm 0.2$ & $40.6 \pm 0.1$ \\
\hline & & & & & & & & $\mathrm{La}_{2} \mathrm{Co}_{1.7}$ & $0.6 \pm 0.1$ & $45.9 \pm 0.3$ & $53.5 \pm 0.2$ \\
\hline & & & & & & & & $\mathrm{La}_{3} \mathrm{Co}$ & $0.0 \pm 0.0$ & $25.7 \pm 0.3$ & $74.3 \pm 0.3$ \\
\hline & & & & & & & & eutectic $\left(\mathrm{La}_{2} \mathrm{Co}_{1.7}+\mathrm{La}_{3} \mathrm{Co}\right)$ & $1.3 \pm 0.3$ & $29.9 \pm 0.9$ & $68.8 \pm 0.9$ \\
\hline & & & & 4.7 & 48.3 & 47.0 & $560{ }^{\circ} \mathrm{C}, 2 \mathrm{~h}$ & $(\alpha \mathrm{Co}, \mathrm{Fe})$ & $61.4 \pm 0.6$ & $38.1 \pm 0.7$ & $0.5 \pm 0.1$ \\
\hline & & & & & & & & $\mathrm{La}_{2} \mathrm{Co}_{3}$ & $2.0 \pm 0.1$ & $57.1 \pm 0.3$ & $40.9 \pm 0.2$ \\
\hline & & & & & & & & $\mathrm{La}_{2} \mathrm{Co}_{1.7}$ & $0.0 \pm 0.0$ & $47.1 \pm 0.3$ & $52.9 \pm 0.3$ \\
\hline \multirow[t]{4}{*}{63} & 5 & 10 & 85 & 5.4 & 12.0 & 82.6 & as-cast & $(\beta \mathrm{La})$ & $0.0 \pm 0.0$ & $0.1 \pm 0.1$ & $99.9 \pm 0.1$ \\
\hline & & & & & & & & $\mathrm{La}_{3} \mathrm{Co}$ & $0.0 \pm 0.0$ & $23.2 \pm 0.1$ & $76.8 \pm 0.1$ \\
\hline & & & & & & & & $\mathrm{La}_{2} \mathrm{Co}_{1.7}$ & $0.9 \pm 0.2$ & $46.1 \pm 0.2$ & $53.0 \pm 0.1$ \\
\hline & & & & & & & & eutectic $\left(\mathrm{La}_{2} \mathrm{Co}_{1.7}+\mathrm{La}_{3} \mathrm{Co}\right)$ & $0.9 \pm 0.5$ & $30.1 \pm 0.9$ & $69.0 \pm 0.8$ \\
\hline \multirow[t]{3}{*}{65} & 2 & 18 & 80 & 1.7 & 18.3 & 80.0 & as-cast & $(\beta \mathrm{La})$ & $0.0 \pm 0.0$ & $0.0 \pm 0.0$ & $100.0 \pm 0.0$ \\
\hline & & & & & & & & $\mathrm{La}_{3} \mathrm{Co}$ & $0.0 \pm 0.0$ & $23.4 \pm 0.3$ & $76.6 \pm 0.3$ \\
\hline & & & & & & & & eutectic $\left((\alpha \mathrm{Co}, \mathrm{Fe})+\mathrm{La}_{3} \mathrm{Co}+(\beta \mathrm{La})\right)$ & $1.7 \pm 0.3$ & $20.2 \pm 0.2$ & $78.1 \pm 0.1$ \\
\hline
\end{tabular}


Table 4 continued

\begin{tabular}{|c|c|c|c|c|c|c|c|c|c|c|c|}
\hline \multirow[t]{3}{*}{$\#$} & \multicolumn{6}{|c|}{ Phase composition, at. $\%$} & \multirow[t]{3}{*}{ Heat treatment } & \multicolumn{4}{|c|}{ EPMA data, at. $\%$} \\
\hline & \multicolumn{3}{|c|}{ Nominal } & \multicolumn{3}{|c|}{ Measured } & & & & & \\
\hline & $\mathrm{Fe}$ & Co & $\mathrm{La}$ & $\mathrm{Fe}$ & Co & $\mathrm{La}$ & & Phase & $\mathrm{Fe}$ & Co & $\mathrm{La}$ \\
\hline \multirow[t]{3}{*}{65} & 2 & 53 & 45 & 1.8 & 51.8 & 46.4 & as-cast & $\mathrm{La}_{2} \mathrm{Co}_{7}$ & $6.3 \pm 0.3$ & $70.5 \pm 0.3$ & $23.2 \pm 0.5$ \\
\hline & & & & & & & & $\mathrm{La}_{2} \mathrm{Co}_{3}$ & $1.1 \pm 0.1$ & $58.3 \pm 0.2$ & $40.6 \pm 0.1$ \\
\hline & & & & & & & & $\mathrm{La}_{2} \mathrm{Co}_{1.7}$ & $0.5 \pm 0.1$ & $46.4 \pm 0.4$ & $53.1 \pm 0.4$ \\
\hline \multirow[t]{4}{*}{66} & 2 & 48 & 50 & 1.9 & 47.5 & 50.6 & as-cast & $\tau$ & $28.2 \pm 0.9$ & $60.0 \pm 0.9$ & $11.8 \pm 0.2$ \\
\hline & & & & & & & & $\mathrm{La}_{2} \mathrm{Co}_{3}$ & $2.3 \pm 0.1$ & $57.1 \pm 0.1$ & $40.6 \pm 0.1$ \\
\hline & & & & & & & & $\mathrm{La}_{2} \mathrm{Co}_{1.7}$ & $0.5 \pm 0.2$ & $45.8 \pm 0.3$ & $53.7 \pm 0.2$ \\
\hline & & & & & & & & eutectic $\left(\mathrm{La}_{2} \mathrm{Co}_{1.7}+\mathrm{La}_{3} \mathrm{Co}\right)$ & $0.7 \pm 0.1$ & $30.2 \pm 0.5$ & $69.1 \pm 0.6$ \\
\hline 67 & 2 & 20 & 78 & 1.1 & 20.4 & 78.5 & as-cast & eutectic $\left((\alpha \mathrm{Co}, \mathrm{Fe})+\mathrm{La}_{3} \mathrm{Co}+(\beta \mathrm{La})\right)$ & $1.1 \pm 0.1$ & $20.4 \pm 0.2$ & $78.5 \pm 0.3$ \\
\hline
\end{tabular}

monovariant curve $P_{1} U_{3}$, separating the fields of primary solidification of $\tau$ and $\mathrm{Co}_{5} \mathrm{La}$, is evident from the observation of the primary $\tau$ in samples \#54, 57, and 62 in contrast to $\mathrm{Co}_{5} \mathrm{La}$ in samples \#5 and \#65 (Fig. 5k).

No alloys were investigated in the primary crystallization field of the $\mathrm{La}_{5} \mathrm{Co}_{19}$ phase, but note that this field is the narrowest and is limited by the composition point of alloy \#65. The monovariant curves $\mathrm{L}+\mathrm{LaCo}_{5} \rightleftarrows \mathrm{La}_{5} \mathrm{Co}_{19}$ $\left(p_{5} U_{1}\right)$ and $\mathrm{L}+\mathrm{La}_{5} \mathrm{Co}_{19} \rightleftarrows \mathrm{La}_{2} \mathrm{Co}_{7}\left(p_{6} U_{1}\right)$ do not extend appreciably into the ternary system. The intersections of these curves give the composition of the liquid $U_{l}$. The composition of the liquid at point $U_{l}$ cannot contain more than 1 at. $\% \mathrm{Fe}$.

The primary solidification field of the $\mathrm{La}_{2} \mathrm{Co}_{7}$ phase is also very small. There were no alloys inside this field, but the border of this field is limited by the composition of alloys \#62, 65, and 66, in which the primary phase is $\tau$, $\mathrm{LaCO}_{5}$, and $\mathrm{La}_{2} \mathrm{Co}_{3}$, respectively (Fig. 5k).

Only alloy \#66 is located in the field of primary solidification of the phase $\mathrm{La}_{2} \mathrm{Co}_{3}$. The solidification of this alloy continues with the formation of the $\mathrm{La}_{2} \mathrm{Co}_{1.7}$ phase, and finishes with the formation of the eutectic $\left(\mathrm{Co}_{1.7} \mathrm{La}_{2}+\mathrm{CoLa}_{3}\right)$.

The primary solidification field of the $\mathrm{Co}_{1.7} \mathrm{La}_{2}$ and $\mathrm{CoLa}_{3}$ phases are very narrow and limited by the composition of alloys \#37, 38, and 39, respectively, in which only a small amount of primary grains of $(\alpha \mathrm{Co}, \mathrm{Fe})$ phase is observed (Fig. 5e). In alloys \#37 and \#38, after primary crystallization of the $(\alpha \mathrm{Co}, \mathrm{Fe})$ phase (black grains), the $\mathrm{La}_{2} \mathrm{Co}_{1.7}$ phase crystallizes, and solidification finishes with the formation of the eutectic $\left(\mathrm{La}_{2} \mathrm{Co}_{1.7}+\mathrm{CoLa}_{3}\right)$ (Fig. 5e). The very small amount of primary $(\alpha \mathrm{Co}, \mathrm{Fe})$ grains in these alloys indicates that the primary crystallization field of the $\mathrm{Co}_{1.7} \mathrm{La}_{2}$ phase does not extend into the ternary system more than up to 2 at.\% Fe (Fig. 5e). In alloy \#39, the
Fig. 5 Microstructure of as-cast alloys of La-Co-Fe system: a 40Ce$50 \mathrm{Co}-10 \mathrm{Fe} \quad(\# 1), \quad \times 1000, \quad(\alpha \mathrm{Co}, \mathrm{Fe})+\tau+\mathrm{La}_{2} \mathrm{Co}_{1.7}+$ eutectic $\left(\mathrm{La}_{2} \mathrm{Co}_{1.7}+\mathrm{La}_{3} \mathrm{Co}\right) ; \quad$ b $20 \mathrm{Fe}-50 \mathrm{Co}-30 \mathrm{La} \quad(\# 8), \quad \times 2000$, $(\gamma \mathrm{Co}, \mathrm{Fe})+\tau+\mathrm{La}_{2} \mathrm{Co}_{3}+\mathrm{La}_{2} \mathrm{Co}_{1.7}+$ eutectic $\quad\left(\mathrm{La}_{2} \mathrm{Co}_{1.7}+\mathrm{La}_{3}\right.$ $\mathrm{Co})$; c $15 \mathrm{Fe}-75 \mathrm{Co}-10 \mathrm{La}(\# 10), \times 2000,(\gamma \mathrm{Co}, \mathrm{Fe})+\mathrm{LaCo}_{13}+\mathrm{LaCo}_{5}$ $+\mathrm{La}_{2} \mathrm{Co}_{7}+\mathrm{La}_{2} \mathrm{Co}_{3} ; \quad$ d $10 \mathrm{Fe}-10 \mathrm{Co}-80 \mathrm{La} \quad(\# 36), \quad \times 2000$, $(\alpha \mathrm{Co}, \mathrm{Fe})+(\beta \mathrm{La})+\mathrm{La}_{3} \mathrm{Co} ; \quad$ e $2 \mathrm{Fe}-33 \mathrm{Co}-65 \mathrm{La} \quad(\# 38), \quad \times 1000$, $(\alpha \mathrm{Co}, \mathrm{Fe})+\mathrm{La}_{2} \mathrm{Co}_{1.7}+$ eutectic $\left(\mathrm{La}_{2} \mathrm{Co}_{1.7}+\mathrm{La}_{3} \mathrm{Co}\right) ; \mathbf{f} 10 \mathrm{Fe}-75 \mathrm{Co}-$ $15 \mathrm{La}(\# 44), \times 2000, \mathrm{LaCo}_{13}+\mathrm{LaCo}_{5}+\mathrm{La}_{2} \mathrm{Co}_{7}+\mathrm{La}_{2} \mathrm{Co}_{3} ; \mathbf{g} 10 \mathrm{Fe}-$ 65Co-25La (\#45), $\times 2000, \mathrm{LaCo}_{13}+\tau+\mathrm{La}_{2} \mathrm{Co}_{7}+\mathrm{La}_{2} \mathrm{Co}_{3}+\mathrm{La}_{2}$ $\mathrm{Co}_{1.7}+$ eutectic $\left(\mathrm{La}_{2} \mathrm{Co}_{1.7}+\mathrm{La}_{3} \mathrm{Co}\right) ;$ h $20 \mathrm{Fe}-55 \mathrm{Co}-25 \mathrm{La}$ (\#46), $\times 2000, \mathrm{LaCo}_{13}+\mathrm{La}_{2} \mathrm{Co}_{3}+\mathrm{La}_{2} \mathrm{Co}_{1.7}+$ eutectic $\left(\mathrm{La}_{2} \mathrm{Co}_{1.7}+\mathrm{La}_{3}\right.$ $\mathrm{Co})$; i $5 \mathrm{Fe}-75 \mathrm{Co}-20 \mathrm{La}(\# 7), \times 1000, \mathrm{LaCo}_{13}+\mathrm{LaCo}_{5}+\mathrm{La}_{5} \mathrm{Co}_{19}$ $+\mathrm{La}_{2} \mathrm{Co}_{7}+\mathrm{La}_{2} \mathrm{Co}_{3}+\mathrm{La}_{2} \mathrm{Co}_{1.7} ; \mathbf{j} 15 \mathrm{Fe}-45 \mathrm{Co}-40 \mathrm{La}(\# 61), \times 2000$, $\tau+\mathrm{La}_{2} \mathrm{Co}_{7}+\mathrm{La}_{2} \mathrm{Co}_{3}+$ eutectic $\left(\mathrm{La}_{2} \mathrm{Co}_{1.7}+\mathrm{La}_{3} \mathrm{Co}\right) ; \mathbf{k} 2 \mathrm{Fe}-53 \mathrm{Co}-$ $45 \mathrm{La}(\# 65), \times 2000, \mathrm{LaCo}_{5}+\mathrm{La}_{2} \mathrm{Co}_{7}+\mathrm{La}_{2} \mathrm{Co}_{3}+\mathrm{La}_{2} \mathrm{Co}_{1.7}$; $12 \mathrm{Fe}-$ 20Co-78La (\#67), $\times 2000$, eutectic $\left((\alpha \mathrm{Co}, \mathrm{Fe})+\mathrm{La}_{3} \mathrm{Co}+(\beta \mathrm{La})\right)$

$(\alpha \mathrm{Co}, \mathrm{Fe})$ phase solidifies as a primary phase, then the $\mathrm{CoLa}_{3}$ phase crystallizes, and solidification finishes with the formation of the ternary eutectic $\left((\alpha \mathrm{Co}, \mathrm{Fe})+(\beta \mathrm{La})+\mathrm{CoLa}_{3}\right)$. Note that the monovariant curve $\mathrm{L} \rightleftarrows(\alpha \mathrm{Co}, \mathrm{Fe})+\mathrm{CoLa}_{3}$ has a saddle point corresponding to the maximum temperature on the solidus surface $(\alpha \mathrm{Co}, \mathrm{Fe})+\mathrm{CoLa}_{3}$ at $540{ }^{\circ} \mathrm{C}$.

Analysis of the microstructure of alloy \#67 showed the presence of a ternary eutectic $\left((\beta \mathrm{La})+(\alpha \mathrm{Fe}, \mathrm{Co})+\mathrm{La}_{3}\right.$ Co). This eutectic is very fine. Therefore, this alloy was heated and cooled in DTA equipment at the rate of $5^{\circ} \mathrm{C} /$ min in order to obtain the solidification morphologies of this alloy. Only the microstructure of this alloy after DTA (Fig. 51) allowed the identification of three phases in the eutectic: ( $\beta \mathrm{La}$ ) (white grains), $\mathrm{La}_{3} \mathrm{Co}$ (gray matrix), and $(\alpha \mathrm{Fe}, \mathrm{Co})$ (black grains). This ternary eutectic was also observed in alloys \#39 and \#64; moreover, in the first alloy the $(\alpha \mathrm{Fe}, \mathrm{Co})$ phase is primary, and in the second alloy $(\beta \mathrm{La})$. The composition of the ternary eutectic 


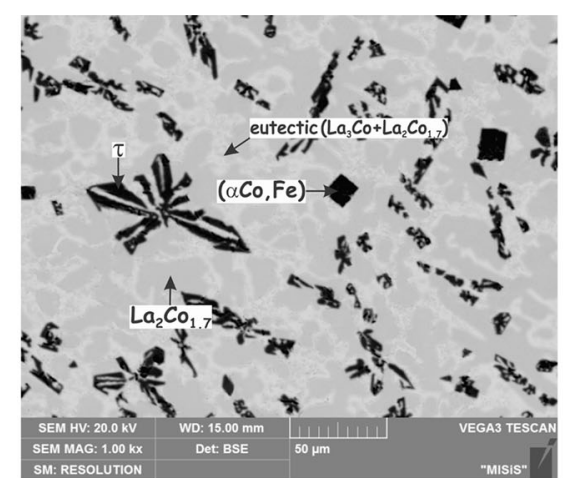

(a)

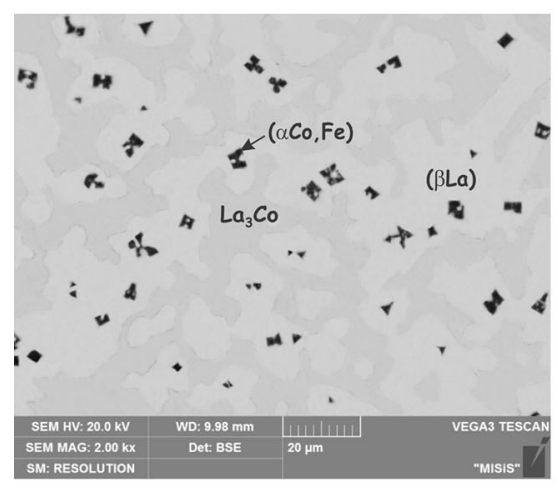

(d)

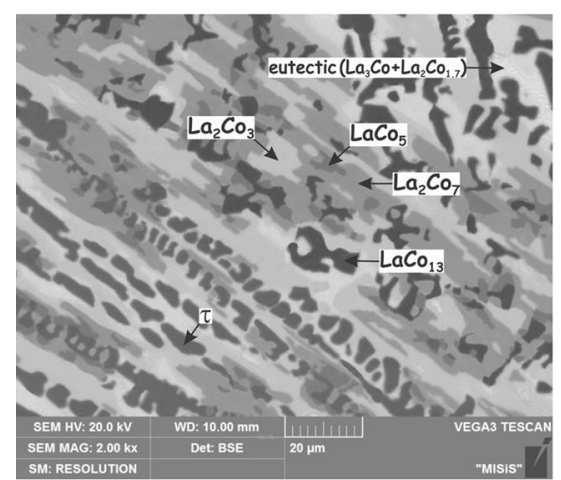

(g)

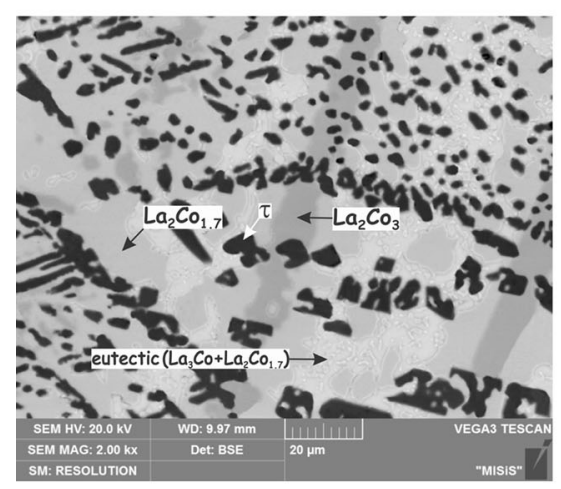

(j)

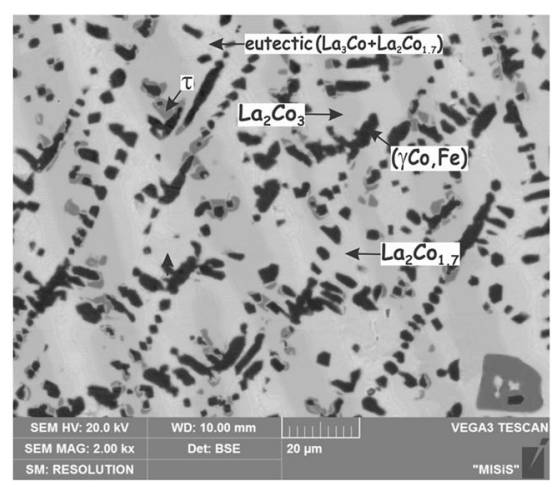

(b)

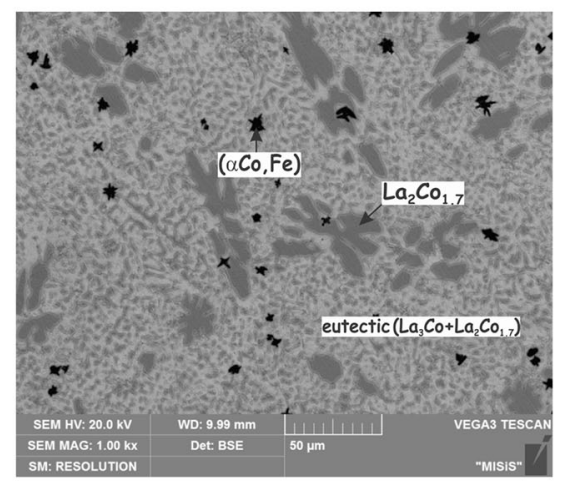

(e)

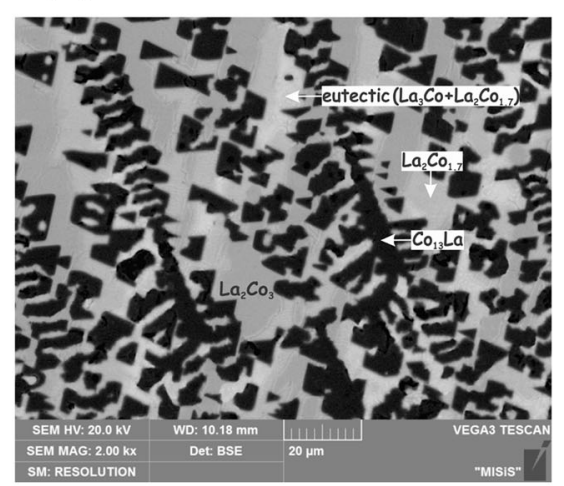

(h)

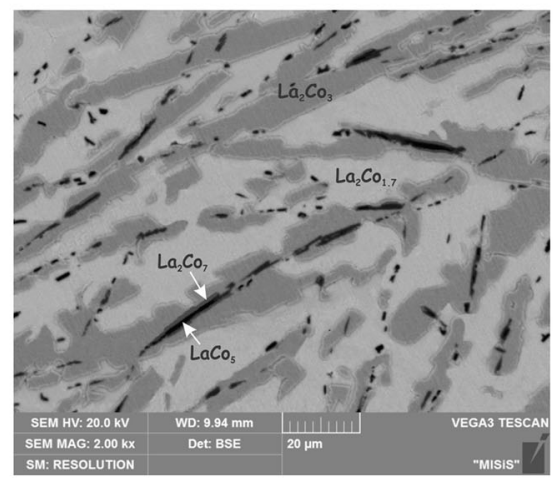

(k)

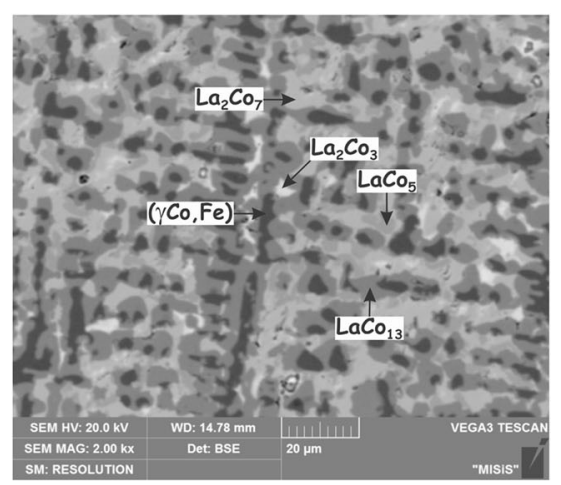

(c)

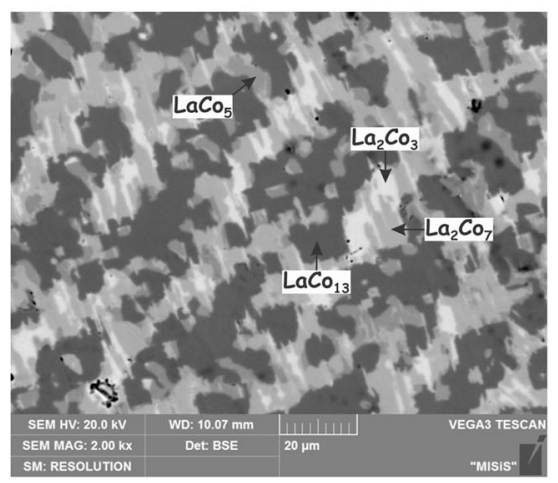

(f)

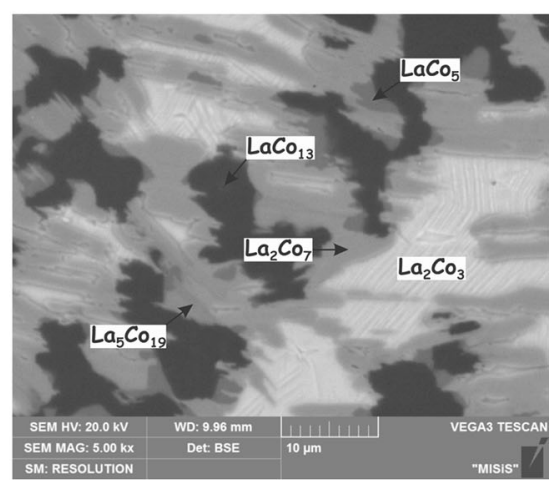

(i)

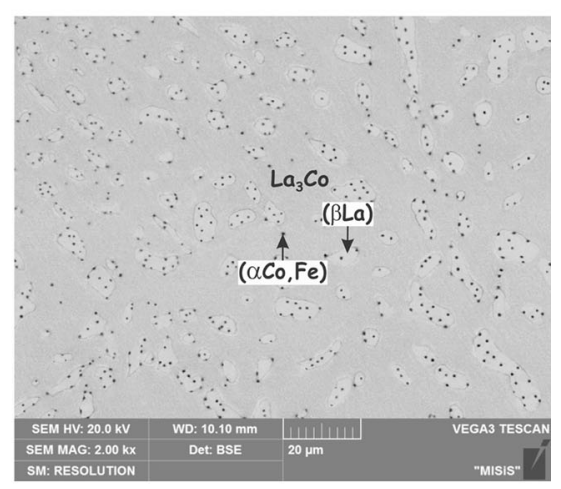

(I) 


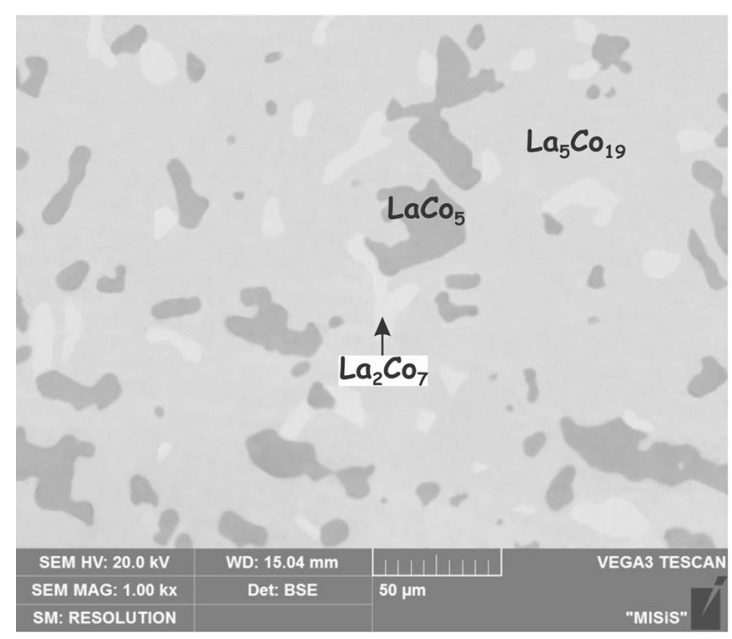

(a)

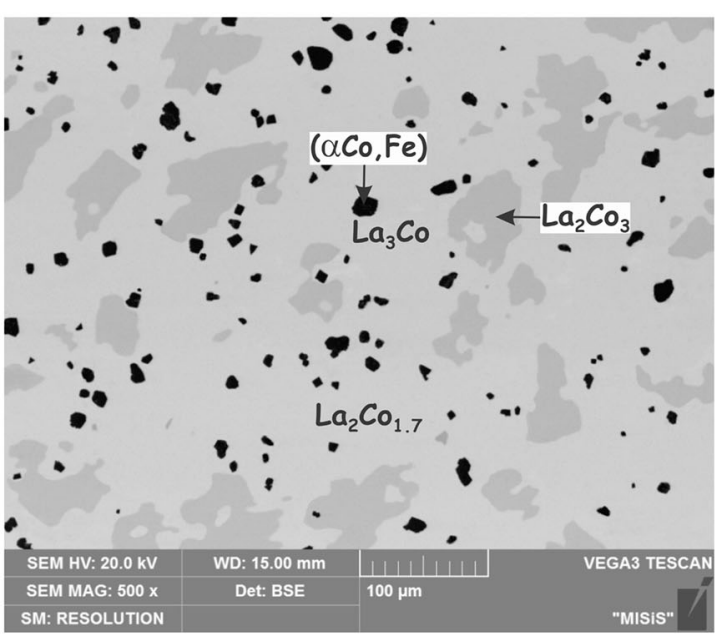

(c)

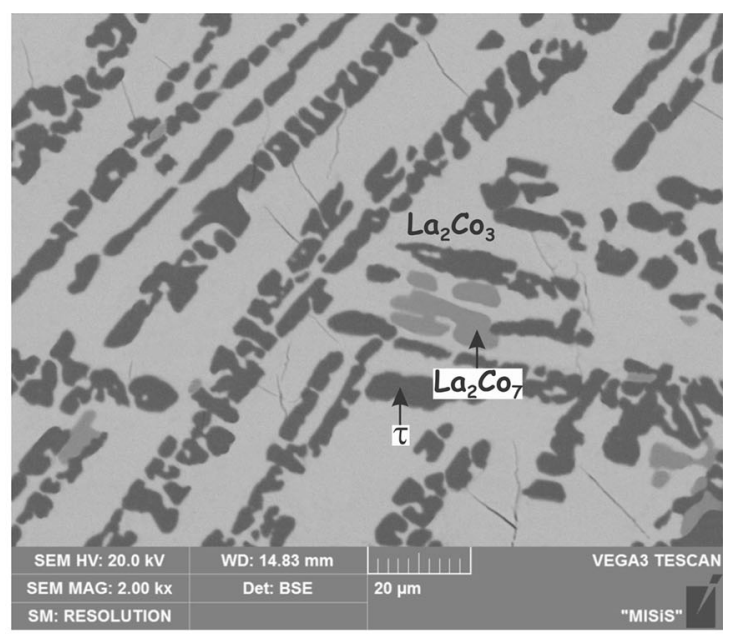

(b)

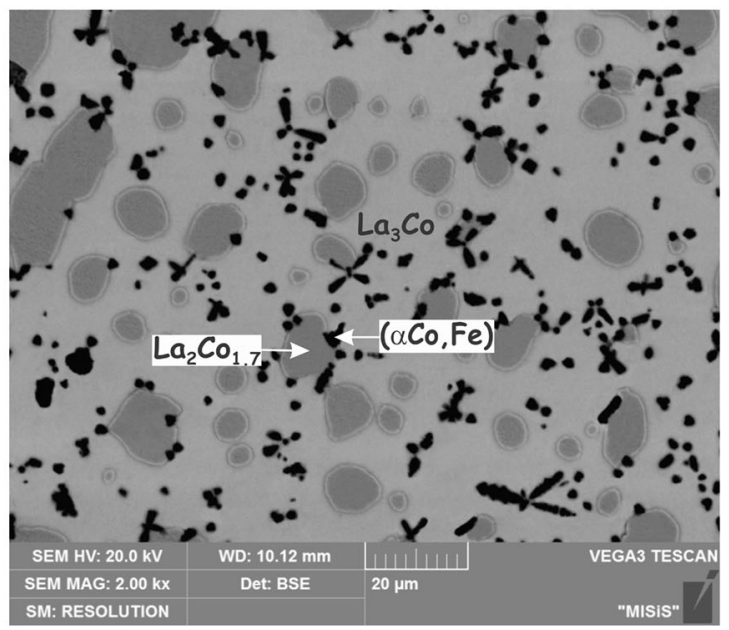

(d)

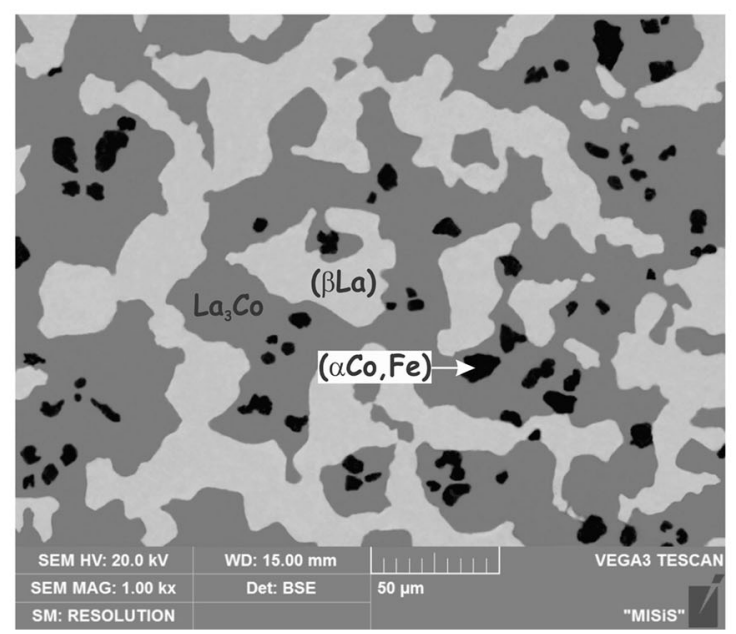

(e)

Fig. 6 Microstructure of alloys of La-Co-Fe system annealed at subsolidus temperatures: a $5 \mathrm{Fe}-75 \mathrm{Co}-20 \mathrm{La}(\# 7), 810^{\circ} \mathrm{C}, \times 2000$, $\mathrm{La}_{2} \mathrm{Co}_{7}+\mathrm{LaCo}_{5}+\mathrm{La}_{5} \mathrm{Co}_{19} ; \quad$ b $10 \mathrm{Fe}-62 \mathrm{Co}-25 \mathrm{La}$ (\#54), $660{ }^{\circ} \mathrm{C}$, $\times 2000, \mathrm{La}_{2} \mathrm{Co}_{3}+\tau+\mathrm{La}_{2} \mathrm{Co}_{7} ;$ c $5 \mathrm{Fe}-50 \mathrm{Co}-45 \mathrm{La}(\# 62), 560{ }^{\circ} \mathrm{C}$, $\times 500,(\alpha \mathrm{Co}, \mathrm{Fe})+\mathrm{La}_{2} \mathrm{Co}_{3}+\mathrm{La}_{2} \mathrm{Co}_{17} ;$ d $10 \mathrm{Fe}-30 \mathrm{Co}-60 \mathrm{La}(\# 34)$ $510{ }^{\circ} \mathrm{C}, \times 2000,(\alpha \mathrm{Co}, \mathrm{Fe})+\mathrm{La}_{3} \mathrm{Co}+\mathrm{La}_{2} \mathrm{Co}_{1.7}$; e $10 \mathrm{Fe}-10 \mathrm{Co}-80 \mathrm{La}$ $(\# 36), 520{ }^{\circ} \mathrm{C}, \times 2000,(\alpha \mathrm{Co}, \mathrm{Fe})+\mathrm{La}_{3} \mathrm{Co}+(\beta \mathrm{La})$ 

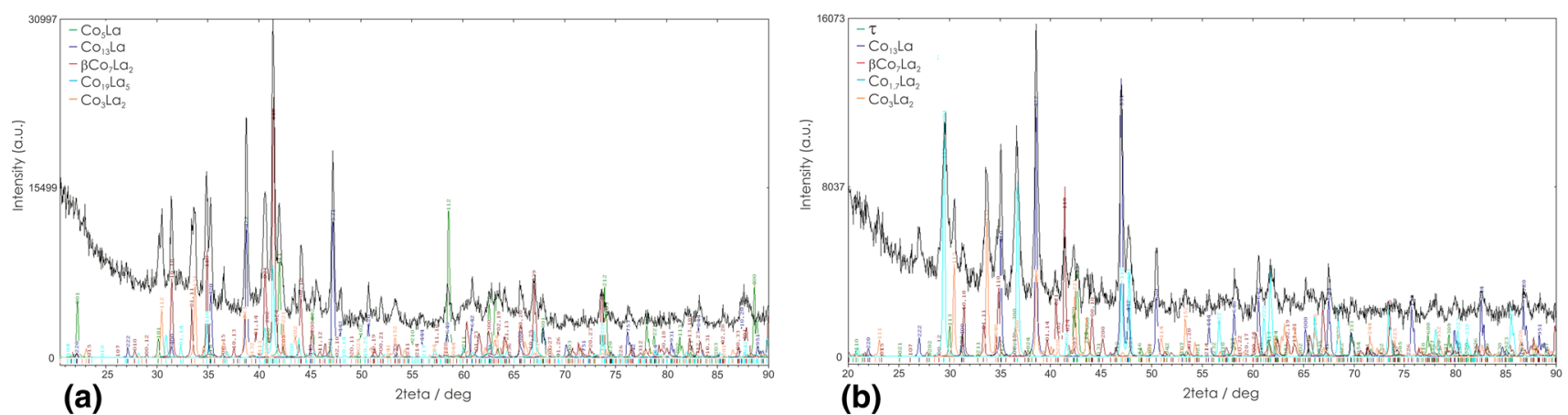

Fig. 7 X-ray diffraction patterns of as-cast alloys in $\mathrm{La}-\mathrm{Co}-\mathrm{Fe}$ system: a $5 \mathrm{Fe}-75 \mathrm{Co}-20 \mathrm{La}(\# 7)$, as-cast, $\mathrm{LaCo}_{13}+\mathrm{LaCo}_{5}+\mathrm{La}_{5} \mathrm{Co}_{19}+\mathrm{La}_{2}$ $\mathrm{Co}_{7}+\mathrm{La}_{2} \mathrm{Co}_{3} ;$ b $15 \mathrm{Fe}-60 \mathrm{Co}-25 \mathrm{La}(\# 50)$, as-cast, $\mathrm{LaCo}_{13}+\tau+\mathrm{LaCo}_{5}+\mathrm{La}_{2} \mathrm{Co}_{3}+\mathrm{La}_{2} \mathrm{Co}_{1.7}$

$\left((\beta \mathrm{La})+(\alpha \mathrm{Fe}, \mathrm{Co})+\mathrm{La}_{3} \mathrm{Co}\right)$ according to the EPMA data of alloys \#64 and 67 is $1.4 \mathrm{Fe}-20.3 \mathrm{Co}-78.3 \mathrm{La}$ (Table 4 , Fig. 51).

The isotherms of the liquidus surface (Fig. 4a) are constructed based on the DTA results (Table 3), and additionally refined via the constructed vertical sections, so that each alloy is involved in at least three sections.

\subsubsection{Solidus Projection}

Figure $4 \mathrm{~b}$ shows the solidus surface projection of the $\mathrm{Fe}-$ Co-La system in the whole composition range resulting from this research. The solidus surface of this system is characterized by the presence of the following threephase regions: $\tau+\mathrm{LaCo}_{13}+\mathrm{LaCo}_{5}, \mathrm{La}_{5} \mathrm{Co}_{19}+\mathrm{LaCo}_{5}$ $+\mathrm{La}_{2} \mathrm{Co}_{7}, \mathrm{La}_{2} \mathrm{Co}_{7}+\tau+\mathrm{La}_{2} \mathrm{Co}_{3}, \mathrm{LaCo}_{5}+\mathrm{La}_{2} \mathrm{Co}_{7}+\tau$, $\tau+(\alpha \mathrm{Co}, \mathrm{Fe})+\mathrm{La}_{2} \mathrm{Co}_{3}, \quad \mathrm{LaCo}_{13}+\tau+(\alpha \mathrm{Co}, \mathrm{Fe}), \quad \mathrm{La}_{2}$ $\mathrm{Co}_{3}+\mathrm{La}_{2} \mathrm{Co}_{1.7}+(\alpha \mathrm{Co}, \mathrm{Fe}), \quad(\alpha \mathrm{Co}, \mathrm{Fe})+\mathrm{La}_{3} \mathrm{Co}+\mathrm{La}_{2}$ $\mathrm{Co}_{1.7},(\alpha \mathrm{Co}, \mathrm{Fe})+\mathrm{La}_{3} \mathrm{Co}+(\beta \mathrm{La})$, and $(\alpha \mathrm{Co}, \mathrm{Fe})+\mathrm{Co}_{13}$ $\mathrm{La}+(\gamma \mathrm{Co}, \mathrm{Fe})$ and the corresponding two-phase regions. The corners of these triangles are plotted using the microprobe results for individual phases (Table 4). The solidus temperatures of the three-phase regions, as measured by DTA (Table 3), are shown in the solidus projection in Fig. 4b.

The existence and position of the very narrow threephase region $\mathrm{La}_{5} \mathrm{Co}_{19}+\mathrm{LaCo}_{5}+\mathrm{La}_{2} \mathrm{Co}_{7}$ with the participation of the $\mathrm{La}_{5} \mathrm{Co}_{19}$ phase is established based on the SEM and EPMA results for alloy \#7 annealed at the solidus temperature $\left(810^{\circ} \mathrm{C}, 4 \mathrm{~h}\right)$ (Table 3, 4, Fig. 6a). The microstructure of this alloy clearly shows three phases (Fig. 6a): dark, gray, and light gray. These correspond to $\mathrm{La}_{5} \mathrm{Co}_{19}, \mathrm{LaCo}_{5}$, and $\mathrm{La}_{2} \mathrm{Co}_{7}$, respectively. The heating curve of this alloy shows that the temperature of the corresponding isothermal plane is $818^{\circ} \mathrm{C}$. Therefore, this three-phase region $\mathrm{La}_{5} \mathrm{Co}_{19}+\mathrm{LaCo}_{5}+\mathrm{La}_{2} \mathrm{Co}_{7}$ is formed via U-type reaction $\mathrm{L}+\mathrm{La}_{5} \mathrm{Co}_{19} \rightleftarrows \mathrm{La}_{2} \mathrm{Co}_{7}+\mathrm{LaCo}_{5}$ taking place at $818^{\circ} \mathrm{C}$.
The SEM and EMPA results of alloys \#45 and 54 annealed at the solidus temperature $\left(660^{\circ} \mathrm{C}, 2 \mathrm{~h}\right)$ clearly show the three phases $\mathrm{La}_{2} \mathrm{Co}_{7}$ (dark-gray grains) $+\tau$ (gray grains) $+\mathrm{La}_{2} \mathrm{Co}_{3}$ (light-gray grains) (Fig. 6b). The composition of the solid phases in this equilibrium was measured by the microprobe method (Table 4). The threephase structure $\left(\mathrm{La}_{2} \mathrm{Co}_{7}+\tau+\mathrm{La}_{2} \mathrm{Co}_{3}\right)$ of these alloys (Fig. 6b) and invariant effects at $673{ }^{\circ} \mathrm{C}$ on their heating curves (Table 3) (corresponding to U-type reaction) determine the position and temperature of the relevant three-phase region.

Two very narrow three-phase regions with the participation of the $\tau$ phase are also formed on the solidus surface in the Co-rich corner: $\tau+\mathrm{LaCo}_{13}+\mathrm{LaCo}_{5}$ and $\mathrm{LaCo}_{5}$ $+\mathrm{La}_{2} \mathrm{Co}_{7}+\tau$. The boundaries of the three-phase region $\tau+\mathrm{LaCo}_{13}+\mathrm{LaCo}_{5}$ are established based on the SEM and EPMA data for the two-phase $\mathrm{LaCo}_{13}+\mathrm{LaCo}_{5}$ alloy $\# 22$, annealed at solidus temperature $\left(970{ }^{\circ} \mathrm{C}, 3 \mathrm{~h}\right)$ and the EPMA data of alloy \#2 containing the $\tau$-phase (Table 4). There were no samples corresponding to this three-phase region; however, it should be pointed out that this region is very narrow. Even though there is no experimental evidence concerning the exact position of this region, it cannot differ substantially from that shown in Fig. 4(b). The high content of Co in the $\tau$-phase (79.3 at.\% according to EPMA data of alloy \#2) leads to the conclusion that alloy \#22 lies very close to the associated boundary tie-lines of the $\tau+\mathrm{LaCo}_{13}+\mathrm{LaCo}_{5}$ three-phase region. The heating curve of this alloy shows that the temperature of the respective isothermal plane is $978{ }^{\circ} \mathrm{C}$ (Table 3). The existence of the $\mathrm{LaCO}_{5}+\mathrm{La}_{2} \mathrm{Co}_{7}+\tau$ three-phase region is obvious in terms of phase equilibrium rules. Since there are no alloys in this composition range, the vertices of the respective tie-line triangle are shown tentatively. The temperature of this isothermal plane $\left(687^{\circ} \mathrm{C}\right)$ is determined from the heating curve of some as-cast alloys (\#45, $47,49)$ in which the respective phase region is not in equilibrium. 
Table 5 Crystal structure and lattice parameters of La-Fe-Co phases

\begin{tabular}{|c|c|c|c|c|}
\hline Phase & Crystal structure & Lattice parameter, $\AA$ & Remarks & Ref. \\
\hline$(\delta \mathrm{Fe})$ & $\mathrm{W}, c I 2-I m-3 m$ & $a=2.9315$ & at $>1394{ }^{\circ} \mathrm{C}$ & [35] \\
\hline$(\gamma \mathrm{Fe})$ & $\mathrm{Cu}, c F 4-F m-3 m$ & $a=3.6467$ & at $>912{ }^{\circ} \mathrm{C}$ & [35] \\
\hline$(\alpha \mathrm{Fe})$ & $\mathrm{W}, c I 2-I m-3 m$ & $a=2.8665$ & at $25^{\circ} \mathrm{C}$ & [35] \\
\hline$(\varepsilon \mathrm{Fe})$ & $\mathrm{Mg}, h P 2-P 6_{3} / m m c$ & $a=2.468, c=3.96$ & at $25^{\circ} \mathrm{C},>13 \mathrm{GPa}$ & [35] \\
\hline$(\gamma \mathrm{La})$ & $\mathrm{W}, c I 2-I m-3 m$ & $a=4.26$ & at $>865^{\circ} \mathrm{C}$ & [35] \\
\hline$(\beta \mathrm{La})$ & $\mathrm{Cu}, c F 4-F m-3 m$ & $a=5.303$ & at $>310{ }^{\circ} \mathrm{C}$ & [35] \\
\hline$(\alpha \mathrm{La})$ & $\alpha \mathrm{La}, h P 4-P 6_{3} / m m c$ & $a=3.7740, c=12.171$ & at $25^{\circ} \mathrm{C}$ & [35] \\
\hline$(\alpha \mathrm{Co})$ & $\mathrm{Cu}, c F 4-F m-3 m$ & $a=3.5447$ & at $>422{ }^{\circ} \mathrm{C}$ & [35] \\
\hline$(\varepsilon \mathrm{Co})$ & $\mathrm{Mg}, h P 2-P 6_{3} / m m c$ & $a=2.5071, c=4.0686$ & at $25^{\circ} \mathrm{C}$ & [35] \\
\hline \multirow[t]{5}{*}{$\mathrm{Co}_{13} \mathrm{La}$} & $\mathrm{NaZn}_{13}, F 112-F m-3 c$ & $a=11.344(1)$ & $1000{ }^{\circ} \mathrm{C}, 3$ days & [27] \\
\hline & & $a=11.386(1)$ & $75 \mathrm{Co}-10 \mathrm{Fe}-15 \mathrm{La}$, as-cast & Th.w. \\
\hline & & $a=11.487(1)$ & $55 \mathrm{Co}-20 \mathrm{Fe}-25 \mathrm{La}$, as-cast & Th.w. \\
\hline & & $a=11.376(1)$ & $75 \mathrm{Co}-5 \mathrm{Fe}-20 \mathrm{La}$, as-cast & Th.w. \\
\hline & & $a=11.437(2)$ & $60 \mathrm{Co}-15 \mathrm{Fe}-25 \mathrm{La}$, as-cast & Th.w. \\
\hline \multirow[t]{4}{*}{$\mathrm{Co}_{5} \mathrm{La}$} & $\mathrm{CaCu}_{5}, h P 6-P 6 / \mathrm{mmm}$ & $a=5.100(5), c=3.968(5)$ & - & [27] \\
\hline & & $a=5.117, c=3.975$ & - & [36] \\
\hline & & $a=5.120(1), c=3.999(1)$ & $75 \mathrm{Co}-10 \mathrm{Fe}-15 \mathrm{La}$, as-cast & Th.w. \\
\hline & & $a=5.101(3), c=4.007(1)$ & $75 \mathrm{Co}-5 \mathrm{Fe}-20 \mathrm{La}$, as-cast & Th.w. \\
\hline \multirow[t]{3}{*}{$\mathrm{Co}_{19} \mathrm{La}_{5}$} & $\mathrm{Ce}_{5} \mathrm{Co}_{19}, h R 72-R-3 m$ & $a=5.123, c=48.74$ & - & [32] \\
\hline & & $a=5.130(1), c=48.82(1)$ & at $1073 \mathrm{~K}$ for $10 \mathrm{~h}$ & [37] \\
\hline & & $a=5.141(2), c=49.50(4)$ & $75 \mathrm{Co}-5 \mathrm{Fe}-20 \mathrm{La}$, as-cast & Th.w. \\
\hline \multirow[t]{5}{*}{$\beta \mathrm{Co}_{7} \mathrm{La}_{2}$} & $\mathrm{Gd}_{2} \mathrm{Co}_{7}, h R 54-R-3 m$ & $a=5.11(1), c=36.69(2)$ & - & [27] \\
\hline & & $a=5.109, c=36.701$ & - & [36] \\
\hline & & $a=5.149(1), c=36.90(2)$ & $75 \mathrm{Co}-10 \mathrm{Fe}-15 \mathrm{La}$, as-cast & Th.w. \\
\hline & & $a=5.141(2), c=36.98(2)$ & $75 \mathrm{Co}-5 \mathrm{Fe}-20 \mathrm{La}$, as-cast & Th.w. \\
\hline & & $a=5.148(1), c=36.953(2)$ & $60 \mathrm{Co}-15 \mathrm{Fe}-25 \mathrm{La}$, as-cast & Th.w. \\
\hline \multirow[t]{2}{*}{$\alpha \mathrm{Co}_{7} \mathrm{La}_{2}$} & $\mathrm{Ce}_{2} \mathrm{Ni}_{7}, h P 36-P 6_{3} / m m c$ & $a=5.101(5), c=24.511(8)$ & - & [27] \\
\hline & & $a=5.109, c=24.523$ & - & [36] \\
\hline \multirow[t]{3}{*}{$\mathrm{Co}_{3} \mathrm{La}_{2}$} & $\mathrm{La}_{2} \mathrm{Ni}_{3}, o S 20-C m c a$ & $a=10.34(1), b=4.886(7), c=7.811(5)$ & - & [27] \\
\hline & & $a=10.373(7), b=4.898(4), c=7.836(5)$ & $75 \mathrm{Co}-5 \mathrm{Fe}-20 \mathrm{La}$, as-cast & Th.w. \\
\hline & & $a=10.366(6), b=4.893(3), c=7.833(5)$ & $60 \mathrm{Co}-15 \mathrm{Fe}-25 \mathrm{La}$, as-cast & Th.w. \\
\hline \multirow[t]{2}{*}{$\mathrm{Co}_{1.7} \mathrm{La}_{2}$} & $\mathrm{Co}_{1.7} \mathrm{La}_{2}, m S 8-C 2 / m$ & $a=8.45361(1), b=4.8807(1), c=4.2723(2)$ & - & [38] \\
\hline & & $a=8.461(1), b=4.897(1), c=4.344(4)$ & $60 \mathrm{Co}-15 \mathrm{Fe}-25 \mathrm{La}$, as-cast & Th.w. \\
\hline $\mathrm{CoLa}_{3}$ & $\mathrm{Fe}_{3} \mathrm{C}, o P 16-P n m a$ & $a=7.277(9), b=10.02(1), c=6.575(8)$ & - & [27] \\
\hline \multirow[t]{2}{*}{$\tau,(\mathrm{Co}, \mathrm{Fe})_{17} \mathrm{La}_{2}$} & $\mathrm{Th}_{2} \mathrm{Zn}_{17}, R-3 m$ & $a=8.524, c=12.37$ & - & [28] \\
\hline & & $a=8.545(2), c=12.44(1)$ & $60 \mathrm{Co}-15 \mathrm{Fe}-25 \mathrm{La}$, as-cast & Th.w. \\
\hline
\end{tabular}

Th.w.- result of this work

The $\tau$-phase in addition to the $\mathrm{LaCo}_{13}, \mathrm{LaCo}_{5}, \mathrm{La}_{2} \mathrm{Co}_{7}$, and $\mathrm{La}_{2} \mathrm{Co}_{3}$ phases is in equilibrium with the $(\alpha \mathrm{Co}, \mathrm{Fe})$ phase, forming two more three-phase regions: $\tau+(\alpha \mathrm{Co}, \mathrm{Fe})+\mathrm{La}_{2} \mathrm{Co}_{3}$ and $\mathrm{LaCo}_{13}+\tau+(\alpha \mathrm{Co}, \mathrm{Fe})$. There were no samples corresponding to these three-phase regions; however, it should be pointed out that these regions are very narrow. Even though there is no experimental evidence concerning the exact position of these regions, it cannot differ substantially from that shown in
Fig. 4(b). The position of the vertices of the respective tieline triangles is determined from the data of neighboring two-phase alloys and the mutual arrangement of the regions of phase homogeneity.

The existence of the three-phase region $(\alpha \mathrm{Co}, \mathrm{Fe})+\mathrm{La}_{2} \mathrm{Co}_{3}+\mathrm{La}_{2} \mathrm{Co}_{1.7}$ and its location were established directly, on the basis of the investigation of three-phase samples. The SEM and EMPA results of alloys \#59 and \#62 annealed at the subsolidus temperature 
Table 6 Invariant equilibria in the $\mathrm{Fe}-\mathrm{Co}-\mathrm{La}$ system

\begin{tabular}{|c|c|c|c|c|c|}
\hline \multirow[t]{2}{*}{ Liquid point } & \multirow[t]{2}{*}{ Invariant equilibrium } & \multirow[t]{2}{*}{ Temperature, ${ }^{\circ} \mathrm{C}$} & \multicolumn{3}{|c|}{ Composition of the liquid, at. $\%$} \\
\hline & & & $\mathrm{Fe}$ & $\mathrm{Co}$ & $\mathrm{La}$ \\
\hline $\mathrm{E}_{1}$ & $\mathrm{~L}_{\mathrm{E} 1} \rightleftarrows \mathrm{La}_{3} \mathrm{Co}+(\beta \mathrm{La})+(\alpha \mathrm{Co}, \mathrm{Fe})$ & 527 & 1.5 & 20.0 & 78.5 \\
\hline $\mathrm{P}_{1}$ & $\mathrm{~L}_{\mathrm{P} 1}+\mathrm{LaCo}_{13}+\mathrm{LaCo}_{5} \rightleftarrows \tau$ & 978 & 9.0 & 64.5 & 26.5 \\
\hline $\mathrm{P}_{2}$ & $\mathrm{~L}_{\mathrm{P} 2}+\mathrm{LaCo}_{13}+(\gamma \mathrm{Co}, \mathrm{Fe}) \rightleftarrows(\alpha \mathrm{Co}, \mathrm{Fe})$ & $\sim 970$ & 17.5 & 45.5 & 37.0 \\
\hline $\mathrm{U}_{1}$ & $\mathrm{~L}_{\mathrm{U} 1}+\mathrm{LaCo}_{13} \rightleftarrows \tau+(\alpha \mathrm{Co}, \mathrm{Fe})$ & $\sim 950$ & 16.5 & 46.5 & 37.0 \\
\hline $\mathrm{U}_{2}$ & $\mathrm{~L}_{\mathrm{U} 2}+\mathrm{La}_{5} \mathrm{Co}_{19} \rightleftarrows \mathrm{LaCo}_{5}+\mathrm{La}_{2} \mathrm{Co}_{7}$ & 818 & 1.0 & 51.5 & 47.5 \\
\hline $\mathrm{U}_{3}$ & $\mathrm{~L}_{\mathrm{U} 3}+\mathrm{LaCo}_{5} \rightleftarrows \tau+\mathrm{La}_{2} \mathrm{Co}_{7}$ & 687 & 2.0 & 50.5 & 47.5 \\
\hline $\mathrm{U}_{4}$ & $\mathrm{~L}_{\mathrm{U} 4}+\mathrm{La}_{2} \mathrm{Co}_{7} \rightleftarrows \tau+\mathrm{La}_{2} \mathrm{Co}_{3}$ & 673 & 2.0 & 47.5 & 50.5 \\
\hline $\mathrm{U}_{5}$ & $\mathrm{~L}_{\mathrm{U} 5}+\tau \rightleftarrows(\alpha \mathrm{Co}, \mathrm{Fe})+\mathrm{La}_{2} \mathrm{Co}_{3}$ & 645 & 5.0 & 41.5 & 53.5 \\
\hline $\mathrm{U}_{6}$ & $\mathrm{~L}_{\mathrm{U} 6}+\mathrm{La}_{2} \mathrm{Co}_{3} \rightleftarrows(\alpha \mathrm{Co}, \mathrm{Fe})+\mathrm{La}_{2} \mathrm{Co}_{1.7}$ & 573 & 2.0 & 37.0 & 61.0 \\
\hline $\mathrm{U}_{7}$ & $\mathrm{~L}_{\mathrm{U} 7}+(\alpha \mathrm{Co}, \mathrm{Fe}) \rightleftarrows \mathrm{La}_{3} \mathrm{Co}+\mathrm{La}_{2} \mathrm{Co}_{1.7}$ & 515 & 0.5 & 31.0 & 68.5 \\
\hline
\end{tabular}

$\left(560{ }^{\circ} \mathrm{C}, 2 \mathrm{~h}\right.$ ) clearly show the three phases (Fig. 6c). The dark and gray regions are the $(\alpha \mathrm{Co}, \mathrm{Fe})$ and $\mathrm{La}_{2} \mathrm{Co}_{3}$ phases, respectively. The light-gray regions correspond to $\mathrm{La}_{2}$ $\mathrm{Co}_{1.7}$. The compositions of the solid phases in these equilibria were measured by the microprobe method (Table 4). According to the DTA data of these alloys and alloys \#8, $31,58,65$, and 66 , the temperature of the respective isothermal plane is $569{ }^{\circ} \mathrm{C}$ (Table 3). This three-phase region is formed by the transition-type reaction $\mathrm{L}+\mathrm{La}_{2}$ $\mathrm{Co}_{3} \rightleftarrows(\alpha \mathrm{Co}, \mathrm{Fe})+\mathrm{La}_{2} \mathrm{Co}_{1.7}$ at $569{ }^{\circ} \mathrm{C}$.

According to the SEM and EPMA results, the alloy \#34, annealed at subsolidus temperature $\left(510{ }^{\circ} \mathrm{C}\right)$, is located in the three-phase region $\mathrm{La}_{3} \mathrm{Co}+\mathrm{La}_{2} \mathrm{Co}_{1.7}+(\alpha \mathrm{Co}, \mathrm{Fe})$. Three phases can be well distinguished in the microstructure of this alloy (Fig. 6d). They were identified as follows: black grains corresponds to $(\alpha \mathrm{Co}, \mathrm{Fe})$, gray and light-gray grains correspond to $\mathrm{La}_{2} \mathrm{Co}_{1.7}$ and $\mathrm{La}_{3} \mathrm{Co}$, respectively. The heating curves of this alloys, as well as as-cast alloys \#1, $15,16,18,20,29,34,35,37$, and 38, show an invariant effect at $515^{\circ} \mathrm{C}$ (Table 3). The types of equilibria are confirmed both by the relative positions of the points of liquid and solid phases in equilibria, and by their temperature in comparison with those of incoming and outgoing ones. A three-phase region of the solidus surface $\mathrm{La}_{3}$ $\mathrm{Co}+\mathrm{La}_{2} \mathrm{Co}_{1.7}+(\alpha \mathrm{Co}, \mathrm{Fe})$ results from a four-phase invariant transition-type reaction $\mathrm{L}+(\alpha \mathrm{Co}, \mathrm{Fe}) \rightleftarrows \mathrm{La}_{3}$ $\mathrm{Co}+\mathrm{La}_{2} \mathrm{Co}_{1.7}$ at $515{ }^{\circ} \mathrm{C}$, rather than a eutectic type. The arguments for this conclusion are as follows: (1) the solidus temperature of the field $\mathrm{La}_{3} \mathrm{Co}+\mathrm{La}_{2} \mathrm{Co}_{1.7}+(\alpha \mathrm{Co}, \mathrm{Fe})$ is higher than the temperature of the eutectic $\mathrm{L} \rightleftarrows \mathrm{La}_{3}$ $\mathrm{Co}+\mathrm{La}_{2} \mathrm{Co}_{1.7}$ in the Co-La binary system (DTA analysis of the binary eutectic alloy 69La-31Co indicates the temperature of the eutectic reaction $\mathrm{L} \rightleftarrows \mathrm{La}_{3} \mathrm{Co}+\mathrm{La}_{2} \mathrm{Co}_{1.7}$ to be $\left.514{ }^{\circ} \mathrm{C}\right)$; (2) in most alloys, the eutectic ( $\mathrm{La}_{3}$ $\mathrm{Co}+\mathrm{La}_{2} \mathrm{Co}_{1.7}$ ) was observed. This could not be observed in the alloys if the invariant equilibrium were of the eutectic type $\mathrm{L} \rightleftarrows(\alpha \mathrm{Co}, \mathrm{Fe})+\mathrm{La}_{3} \mathrm{Co}+\mathrm{La}_{2} \mathrm{Co}_{1.7}$. To confirm this experimentally, a comparative thermal analysis, at a very low heating rate of $5^{\circ} \mathrm{C} / \mathrm{min}$, was carried out on the ternary alloy \#38 and the binary eutectic alloy 69La$31 \mathrm{Co}$. It was observed that the binary alloy began to melt earlier than the ternary alloy. Further DTA tests at a heating rate of $5 \mathrm{~K} / \mathrm{min}$ revealed that the temperatures of the ternary alloy \#38 and binary alloy 69La-31Co were $515{ }^{\circ} \mathrm{C}$ and $514{ }^{\circ} \mathrm{C}$, respectively.

There is one additional isothermal plane, $(\alpha \mathrm{Co}, \mathrm{Fe})+\mathrm{La}_{3} \mathrm{Co}+(\beta \mathrm{La}), \quad$ involving the $(\alpha \mathrm{Co}, \mathrm{Fe})-$ phase, which forms on the solidus surface. The boundaries of this three-phase region are established based on the SEM and EPMA data for the three-phase region $(\alpha \mathrm{Co}, \mathrm{Fe})$ (black grains $)+\mathrm{La}_{3} \mathrm{Co}$ (gray grains) $+(\beta \mathrm{La})$ (light-gray grains) for alloy \#36 annealed at the subsolidus temperature $\left(520{ }^{\circ} \mathrm{C}, 2 \mathrm{~h}\right.$ ) (Table 4 , Fig. 6e). The heating curve of this alloy, as well as as-cast alloys \#39, 63, 64, and 67, shows an invariant effect at $527{ }^{\circ} \mathrm{C}$ (Table 3). This three-phase region forms via eutectic-type reaction $\mathrm{L} \rightleftarrows(\alpha \mathrm{Co}, \mathrm{Fe})+\mathrm{La}_{3} \mathrm{Co}+(\beta \mathrm{La})$ at $527^{\circ} \mathrm{C}$. The eutectic type of this equilibrium is confirmed by the ternary eutectic microstructure $(\alpha \mathrm{Co}, \mathrm{Fe})+\mathrm{La}_{3} \mathrm{Co}+(\beta \mathrm{La})$ of alloy \#37 (Fig. 51).

\subsubsection{Invariant Equilibria}

The superposition of the liquidus and solidus surfaces of the $\mathrm{Fe}-\mathrm{Co}-\mathrm{La}$ system in the form of a melting diagram is shown in Fig. 4(c). The three-phase regions of the solidus 


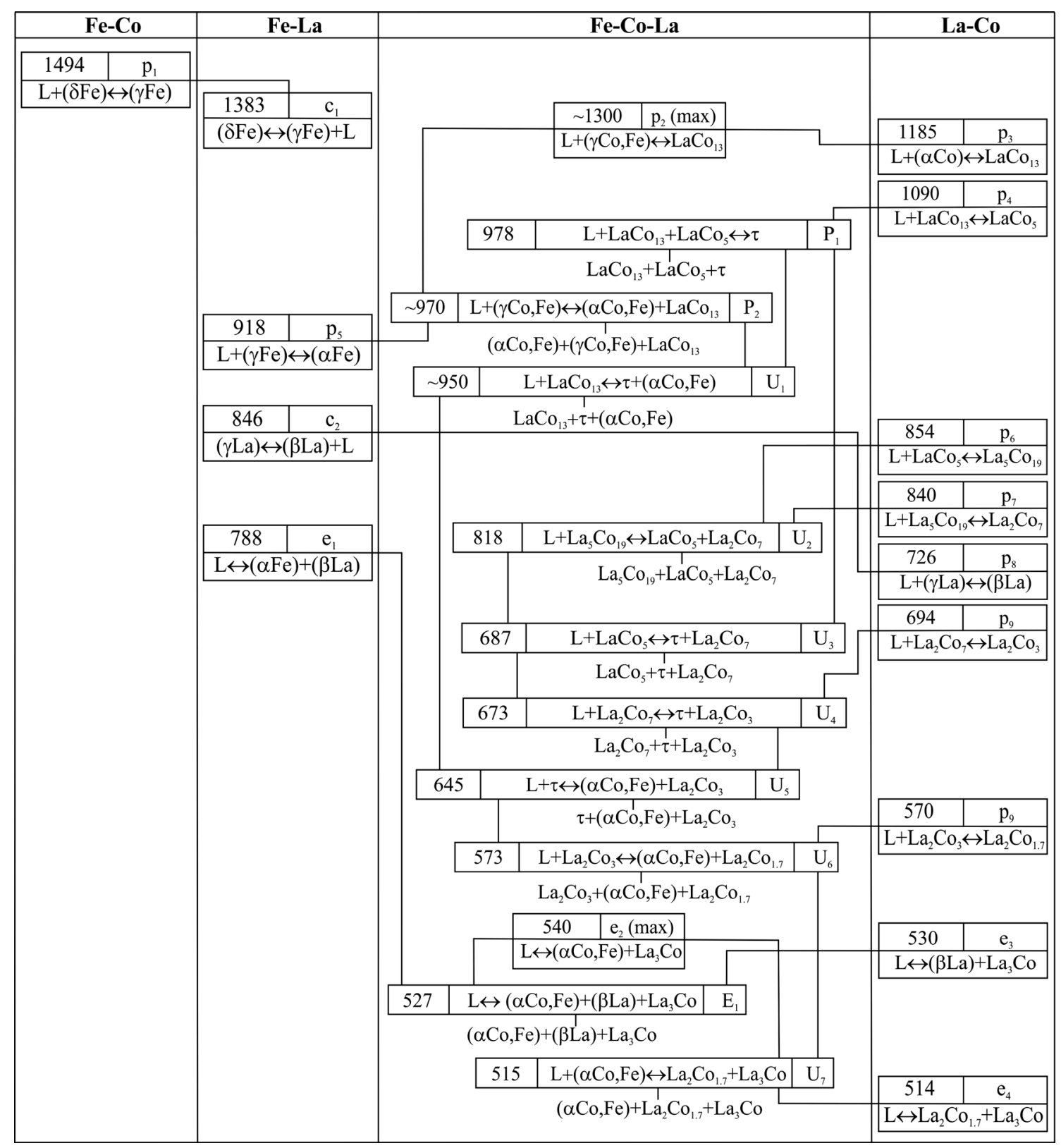

Fig. 8 Scheil diagram for solidification of La-Co-Fe alloys

surface are the result of invariant four-phase reactions. Three-phase fields at the solidus surface result from one eutectic $\mathrm{L}_{\mathrm{E} 1} \rightleftarrows \mathrm{La}_{3} \mathrm{Co}+(\beta \mathrm{La})+(\alpha \mathrm{Co}, \mathrm{Fe})$, two peritectic $\mathrm{L}_{\mathrm{P} 1}+\mathrm{LaCo}_{13}+\mathrm{LaCo}_{5} \rightleftarrows \tau$ and $\mathrm{L}_{\mathrm{P} 2}+$ $(\gamma \mathrm{Co}, \mathrm{Fe})+\mathrm{Co}_{13} \mathrm{La} \rightleftarrows(\alpha \mathrm{Co}, \mathrm{Fe})$, and seven U-type fourphase invariant equilibria $\mathrm{L}_{\mathrm{U} 1}+\mathrm{LaCo}_{13} \rightleftarrows(\alpha \mathrm{Co}, \mathrm{Fe})+\tau$, $\mathrm{L}_{\mathrm{U} 2}+\mathrm{La}_{5} \mathrm{Co}_{19} \rightleftarrows \mathrm{LaCO}_{5}+\mathrm{La}_{2} \mathrm{Co}_{7}, \quad \mathrm{~L}_{\mathrm{U} 3}+\mathrm{LaCo}_{5} \rightleftarrows$ $\tau+\mathrm{La}_{2} \mathrm{Co}_{7}, \mathrm{~L}_{\mathrm{U} 4}+\mathrm{La}_{2} \mathrm{Co}_{7} \rightleftarrows \tau+\mathrm{La}_{2} \mathrm{Co}_{3}, \mathrm{~L}_{\mathrm{U} 5}+\tau \rightleftarrows$ $(\alpha \mathrm{Co}, \mathrm{Fe})+\mathrm{La}_{2} \mathrm{Co}_{3}, \quad \mathrm{~L}_{\mathrm{U} 6}+\mathrm{La}_{2} \mathrm{Co}_{3} \rightleftarrows(\alpha \mathrm{Co}, \mathrm{Fe})+\mathrm{La}_{2}$ $\mathrm{Co}_{1.7}$, and $\mathrm{L}_{\mathrm{U} 7}+(\alpha \mathrm{Co}, \mathrm{Fe}) \rightleftarrows \mathrm{La}_{3} \mathrm{Co}+\mathrm{La}_{2} \mathrm{Co}_{1.7}$, taking place at 527, 978, 970, 950, 818, 687, 673, 645, 569, and $515{ }^{\circ} \mathrm{C}$, respectively. In the two-phase areas $(\gamma \mathrm{Co}, \mathrm{Fe})+\mathrm{LaCo}_{13}$ and $(\alpha \mathrm{Co}, \mathrm{Fe})+\mathrm{La}_{3} \mathrm{Co}$, the solidus surface has maximum temperatures of $\sim 1300$ and $540{ }^{\circ} \mathrm{C}$, respectively. All invariant equilibria are summarized in Table 6. Figure 8 shows the Scheil diagram for the solidification of Co-Fe-La alloys.

\section{Conclusions}

Phase equilibria in the Fe-Co-La system over the whole concentration range during solidification have been studied using DTA, X-ray diffraction analysis, SEM, and electron probe microanalysis. Liquidus and solidus projections, as 
well as the melting diagram and a Scheil diagram were constructed for this system.

The ternary compound $(\mathrm{Co}, \mathrm{Fe})_{17} \mathrm{La}_{2}(\tau)$ forms by peritectic reaction $\mathrm{L}_{\mathrm{P} 1}+\mathrm{LaCo}_{13}+\mathrm{LaCo}_{5} \rightleftarrows \tau$ at $978{ }^{\circ} \mathrm{C}$ and has a wide homogeneity range from 45.8 to 79.5 at.\% Co at solidus temperature, which is linear and located along the isoconcentrate of $\sim 11$ at.\% La.

The $\mathrm{Co}_{13} \mathrm{La}$ phase has the widest homogeneity range at solidus temperature and dissolves up to 43.3 at.\% Fe.

Acknowledgments The study was supported by Russian Science Foundation project no. 18-73-10219.

\section{References}

1. K.H.J. Buschow, Intermetallic Compounds of Rare-Earth and 3d Transition Metals, Rep. Prog. Phys., 1977, 40(10), p 1179-1256

2. K.H.J. Buschow, Hydrogen Absorption in Intermetallic Compounds, Handbook on the Physics and Chemistry of Rare Earths, Vol 6, 1984, p 1-111

3. W.E. Wallace and M. Aoyagi, Magnetische Eigenschaften der Lanthanid-Nickel-Verbindungen $\mathrm{LnNi}_{5}$, Monatsh. Chem., 1971, 102(5), p 1455-1461

4. F. Pourarian, A. Pedziwiatr, and W.E. Wallace, Magnetic Properties of $\mathrm{RNi}_{4} \mathrm{Fe}$ Alloys (R = La, Ce, or Y), J. Appl. Phys., 1984, 55(6), p 1981-1983

5. F. Pourarian, M.Z. Liu, B.Z. Lu, M.Q. Huang, and W.E. Wallace, Magnetic and Crystallographic Characteristics of $\mathrm{CeNi}_{5-\mathrm{x}} \mathrm{M}_{\mathrm{x}}$ ( $\mathrm{M}=\mathrm{Fe}, \mathrm{Mn})$ Alloys and Their Hydrides, J. Solid State Chem., 1986, 65(1), p 111-117

6. M.Q. Huang, W.E. Wallace, M.E. McHenry, Q. Chen, and B.M. Ma, Soft Magnetic Properties of $\mathrm{LaCo} 13$ and $\mathrm{La}(\mathrm{Co}, \mathrm{Fe}) 13$ alloys, J. Appl. Phys., 1998, 83(11), p 6471-6473

7. W. Velge and K.H.J. Buschow, Magnetic and Crystallographic Properties of Some Rare Earth Cobalt Compounds with $\mathrm{CaZn}_{5}$ Structure, J. Appl. Phys., 1968, 39(3), p 1717-1720

8. R.A. Guidotti, G.B. Atkinson, and M.M. Wong, Hydrogen Absorption by Rare Earth-Transition Metal Alloys, J. Less Common Met., 1977, 52(1), p 13-28

9. G. Sandrock, A Panoramic Overview of Hydrogen Storage Alloys from a Gas Reaction Point of View, J. Alloys Compd., 1999, 293, p 877-888

10. M. Mardani, I. Fartushna, A. Khvan, V. Cheverikin, and A. Dinsdale, Experimental Investigation of Phase Transformations in the La-Fe and La-Fe-C Systems, Calphad, 2019, 65, p 370-384

11. A.V. Khvan, I.V. Fartushna, M. Mardani, A.T. Dinsdale, and V.V. Cheverikin, An Experimental Investigation of the Liquidus Projection in the Fe-Ce-C System, J. Alloys Compd., 2015, 651, p 350-356

12. M. Mardani, I. Fartushna, A. Khvan, V. Cheverikin, D. Ivanov, and A. Dinsdale, Phase Equilibria in the Fe-Ce-C System at $1100^{\circ} \mathrm{C}$, J. Alloys Compd., 2018, 730, p 352-359

13. A.V. Khvan, M. Mardani, I.V. Fartushna, E.A. Syutkin, V.V. Cheverikin, and A.T. Dinsdale, An Experimental Investigation of Thermodynamic Properties of $\beta$ - $\mathrm{Fe}_{17} \mathrm{Ce}_{2}, \mathrm{Fe}_{2} \mathrm{Ce}$, and Ternary $\mathrm{Fe}_{13.1-11.0} \mathrm{Mn}_{3.9-6.0} \mathrm{Ce}_{2}\left(\tau_{1}\right)$ Phase, Thermochim. Acta, 2019, 672, p $1-8$

14. I. Fartushna, A. Khvan, A. Dinsdale, V. Cheverikin, D. Ivanov, and A. Kondratiev, An Experimental Investigation of Liquidus and Solidus Projections for the Fe-Mn-Ce System, J. Alloys Compd., 2016, 654, p 424-434
15. I. Fartushna, A. Khvan, A. Dinsdale, V. Cheverikin, D. Ivanov, and A. Kondratiev, Phase Equilibria in the Fe-Mn-Ce System at $900^{\circ} \mathrm{C}, \mathrm{J}$. Alloys Compd., 2016, 658, p 331-336

16. I. Fartushna, M. Mardani, A. Khvan, E. Donkor, V. Cheverikin, A. Kondratiev, and A. Dinsdale, Investigation of Phase Equilibria in the Ce-Co-Fe System during Solidification, J. Alloys Compd., 2018, 735, p 1682-1693

17. I. Fartushna, M. Mardani, A. Khvan, V. Cheverikin, D. Ivanov, A. Kondratiev, and A. Dinsdale, Phase Equilibria in the Ce-Co-Fe System at $900^{\circ} \mathrm{C}, \mathrm{J}$. Alloys Compd., 2018, 765, p 644-649

18. M. Mardani, I. Fartushna, A. Khvan, V. Cheverikin, and A. Dinsdale, Experimental Investigation of Phase Equilibria in the Ce-Fe-Ni System, J. Alloys Compd., 2019, 781, p 524-540

19. I. Fartushna, M. Mardani, A. Khvan, V. Cheverikin, M. Gorshenkov, and A. Dinsdale, Experimental Investigation of Phase Equilibria in the Ce-Fe-Ni System at 950 and $750^{\circ} \mathrm{C}$, Calphad, 2019, 64, p 284-291

20. K.A. Gschneidner, Jr., and F.W Calderwood, Intra Rare Earth Binary Alloys: Phase Relationships, Lattice Parameters and Systematics, Handbook on the Physics and Chemistry of Rare Earths, Vol 8, 1986, p 1-161

21. O. Kubaschewski, Iron-Binary Phase Diagrams, Springer-Verlag, Berlin, 1982, p 57-59

22. H. Okamoto, Fe-La (Iron-Lanthanum), Phase Diagrams of Binary Iron Alloys, ASM International, Materials Park, 1993, p 192193

23. W. Zhang and C. Li, The Fe-La (Iron-Lanthanum) System, J. Phase Equilib., 1997, 18(3), p 301-304

24. R. Marazza, P. Riani, and G. Cacciamani, Critical Assessment of Iron Binary Systems with Light Rare Earths $\mathrm{La}, \mathrm{Ce}, \mathrm{Pr}$, and $\mathrm{Nd}$, Inorg. Chim. Acta, 2008, 361, p 3800-3806

25. I. Ohnuma, H. Enoki, O. Ikeda, R. Kainuma, H. Ohtani, B. Sundman, and K. Ishida, Phase Equilibria in the Fe-Co Binary System, Acta Mater., 2002, 50, p 379-393

26. C.P. Wang, J. Wang, X.J. Liu, I. Ohnuma, R. Kainuma, and K. Ishida, Thermodynamic Assessment of the Co-La and Mo-La Systems, J. Alloys Compd., 2008, 453(1-2), p 174-179

27. K.H.J. Buschow and W.A.J.J. Velge, Phase Relations and Intermetallic Compounds in the Lanthanum-Cobalt System, J. Less Common Met., 1967, 13, p 11-17

28. O.I. Kharchenko, O.I. Bodak, E.I. Gladyshevskii, and B.I. Mazurenko, The Lanthanum-Iron-Cobalt System, Visnik L'vivs'kogo (Derzhavnogo) Universitetu, Seriya Khimichna, 1975, 17, p 16-20, in Ukrainian

29. Kraus W., Nolze G., POWDERCELL, Rev. 1.8a, Federal Institute for Materials Research and Testing (BAM), Berlin (1996).

30. WINXPOW Software, Stoe \& Cie GmbH Darmstadt (1998).

31. A.E. Ray and K.J. Strnat, Magnetic Properties of Rare Earth Cobalt Phase $\mathrm{R}_{5} \mathrm{Co}_{19}$, IEEE Trans. Magn., 1975, 11(5), p 14291430

32. A.E. Ray, Review of the Binary Rare Earth-Co Alloy Systems, Cobalt, 1974, 1, p 13-20

33. Bodak O.I., Kharchenko O.I., Investigation of the interaction of yttrium and lanthanum with metals of the iron family. Tezisy Dokladov - Vsesoyuznaya Konferentsiya po Kristallokhimii Intermetallicheskikh Soedinenii, 2nd (Summaries of Reports, AllUnion Conference on the Crystal Chemistry of Intermetallic Compounds), Lvov (1974) 12, in Russian.

34. V. Raghavan, The Co-Fe-La (Cobalt-Iron-Lanthanum) System, Phase Diagrams of Ternary Iron Alloys, Indian Inst. Met. Calcutta, 1992, 6A, p 615-617

35. T.B. Massalski, Ed., Binary Alloy Phase Diagrams, 2nd ed., ASM International, Metals Park, OH, 1990

36. Y. Khan, Intermetallic Compounds in the Cobalt-Rich Part of the $\mathrm{R}-$ Cobalt Systems $(\mathrm{R}=\mathrm{Ce}, \mathrm{La}, \mathrm{Ce}-\mathrm{La})$, J. Less. Common Met., 1974, 34(2), p 191-200 
37. K. Iwase, T. Ueno, and K. Mori, Crystal Structure and Hydrogen Absorption-Desorption Property of $\mathrm{La}_{5} \mathrm{Co}_{19}$, Int. J. Hydrogen Energy, 2019, 44(41), p 23172-23178

38. M. Dusek, G. Chapuis, P. Schobinger Papamantellos, C. Wilkinson, V. Petricek, L.D. Tung, and K.H.J. Buschow, Modulated Structure of $\mathrm{La}_{2} \mathrm{Co}_{1.7}$ from Neutron and X-Ray
Diffraction Data, Acta Crystallograph. Sect. B Struct. Sci., 2000, 56, p 959-971

Publisher's Note Springer Nature remains neutral with regard to jurisdictional claims in published maps and institutional affiliations. 